NBER WORKING PAPER SERIES

\title{
CRYPTOCURRENCIES, CURRENCY COMPETITION, AND THE IMPOSSIBLE TRINITY
}

\author{
Pierpaolo Benigno \\ Linda M. Schilling \\ Harald Uhlig \\ Working Paper 26214 \\ http://www.nber.org/papers/w26214 \\ NATIONAL BUREAU OF ECONOMIC RESEARCH \\ 1050 Massachusetts Avenue \\ Cambridge, MA 02138
}

August 2019, Revised February 2022

Financial support from the Fondation Banque de France is gratefully acknowledged. We thank Peter DeMarzo, Jonathan Berk, Dirk Niepelt, Maurice Obstfeld, participants of the 2019 ESSFM Gerzensee conference, Paul Pichler, Dirk Niepelt, Raphael Auer, Stephanie Schmitt-Grohé and ISOM 2021 participants for very insightful comments. Pierpaolo Benigno acknowledges support from the Swiss National Science Foundation, Grant No. 100018_197669. Linda's work was partially conducted in the framework of the Chair 'Blockchain and B2B Platforms' at École Polytechnique. The project partially evolved during a research stay of Linda Schilling at the Simons Institute at UC Berkeley. Support and hospitality is gratefully acknowledged. The views expressed herein are those of the authors and do not necessarily reflect the views of the National Bureau of Economic Research.

NBER working papers are circulated for discussion and comment purposes. They have not been peer-reviewed or been subject to the review by the NBER Board of Directors that accompanies official NBER publications.

(C) 2019 by Pierpaolo Benigno, Linda M. Schilling, and Harald Uhlig. All rights reserved. Short sections of text, not to exceed two paragraphs, may be quoted without explicit permission provided that full credit, including $(\odot$ notice, is given to the source. 
Cryptocurrencies, Currency Competition, and the Impossible Trinity

Pierpaolo Benigno, Linda M. Schilling, and Harald Uhlig

NBER Working Paper No. 26214

August 2019, Revised February 2022

JEL No. D53,E4,F31,G12

\begin{abstract}
$\underline{\text { ABSTRACT }}$ Impossible Trinity becomes even less reconcilable.

Pierpaolo Benigno

Dipartiment of Economics

University of Bern

3003 Bern

Switzerland

pierpaolo.benigno@vwi.unibe.ch

Linda M. Schilling

Ecole Polytechnique CREST

5 Avenue le Chatelier

Palaiseau, Fran 91120

France

and CEPR

lin.schilling@gmail.com

Harald Uhlig

Dept. of Economics

University of Chicago

1126 E 59th Street

Chicago, IL 60637

and CEPR

and also NBER

huhlig@uchicago.edu
\end{abstract}

We analyze a two-country economy with complete markets, featuring two national currencies as well as a global (crypto)currency. If the global currency is used in both countries, the national nominal interest rates must be equal and the exchange rate between the national currencies is a risk-adjusted martingale. Deviation from interest rate equality implies the risk of approaching the zero lower bound or the abandonment of the national currency. We call this result CryptoEnforced Monetary Policy Synchronization (CEMPS). If the global currency is backed by interest-bearing assets, additional and tight restrictions on monetary policy arise. Thus, the classic 


\section{Motivation}

Globally usable cryptocurrencies are on the rise. 10 years after the introduction of Bitcoin, a Facebook-led consortium had sought to launch Diem, designed to appeal to the more than 2 billion world-wide Facebook users. Other companies are not far behind. While the Diem project itself has run into headwinds and may be scrapped altogether, it is not implausible that a privately issued and globally usable digital currency with widespread adoption will arise within the next two decades. Already, El Salvador has adopted Bitcoin as legal tender. Alternatively, one of the emerging central bank digital currencies may become a global means of payments in retail markets. Other means of payment have reached worldwide usage before, but the ease of use and the scope of these new digital currencies are about to create global currencies of an altogether different quality. How will they alter the financial landscape? How will this affect exchange rates and monetary policies of traditional currencies?

Global currencies are not a new phenomenon. The Spanish Dollar in the 17th and 18th centuries, gold during the gold standard period, the Pound Sterling prior to 1944, and the U.S. Dollar since then served as an internationally accepted unit of account. In dollarized countries, prices and contracts might be expressed in dollar, while the local currency often still serves as the main medium of exchange, with the occasional country, where expensive goods or even houses were indeed bought with suitcases of 100 dollar bills. The new cryptocurrencies, however, fully seek to become an internationally accepted means of payment, thus directly competing with national currencies for transaction purposes, even as prices are still expressed in, say, Dollars and Euros. We argue that this feature, together with the consequences for national monetary policies, is a qualitatively new phenomenon, see Section 8 .

We thus analyze a general and minimalistic framework of a two-country economy featuring a home, a foreign and a global (crypto)currency. Our focus is on the function of money as medium of exchange: currencies provide liquidity services. Interest-bearing bonds compete against money as a store of value. In Section 7, we show that our framework nests a number of standard approaches 
in the monetary economics literature. Our approach thus encompasses a wide range of monetary approaches and strips them down to their key common component for the analysis at hand.

For the benchmark case that markets are complete, that liquidity services on currency are rendered immediately and that the global currency is used in both countries, we show that nominal interest rates must be equal (Proposition 4.1). We call this phenomenon a crypto-enforced monetary policy synchronization (CEMPS). The escape options for central banks are unpleasant. Lowering the interest rate in order to deter the global currency from circulation at home risks being trapped at the zero lower bound. When increasing interest rates relative to the foreign interest rate, we show that the central bank risks the abandonment of its own national currency as a medium of exchange. If the global currency is backed by interest-bearing assets, additional and tight restrictions on monetary policy arise, see Section 5. In particular, the central bank may be forced to the zero lower bound when the global currency consortium seeks to keep its currency in use per selecting appropriately low and competitive fees.

Our implications can be understood as a strengthened version of the MundellFleming Trilemma (Fleming, 1962; Mundell, 1960, 1963), or the Impossible Trinity. According to this cornerstone result in international economics, it is impossible to ensure a fixed exchange rate, free capital flows and an independent monetary policy all at the same time. In our framework, we allow for a flexible exchange rate and assume free capital flows: nevertheless, to defend the usage of their own national currency, presumably independent central banks have to coordinate their monetary policies. More broadly, our results are reminiscent of Rey (2015), where the Trilemma is transformed into a "Dilemma" or an "irreconcilable" duo. While the global financial cycle is the culprit in her analysis, on ours, it is the worldwide diffusion of a global currency. Furthermore, we contribute to the debate on how currency competition through globalization influences the central bank's capacity to impact the economy, see Romer (2007). 


\section{$1.1 \quad$ Literature}

Our paper contributes to three literature strands in particular. The first is the literature on the international role of currencies and the interdependence of monetary policies. The second is the literature on currency competition and the emerging literature on cryptocurrencies. Finally, we contribute to the monetary economics literature examining the role of money as a medium of exchange.

As for the first, the literature on international currencies and the interdependence of monetary policy, our paper is related to the classic contributions by Mundell (1960), Fleming (1962) and Mundell (1963), and the vast literature following it (see Boughton (2003), Obstfeld et al. (2003) for reviews and Obstfeld and Rogoff (1996) for a textbook treatment). Our result can be read as a sharp contrast to Obstfeld and Rogoff (2002), who argue that in an economy with integrated international financial markets, monetary policymakers have the ability to control their monetary instruments to achieve their target. Instead, our work shows that, under the same assumptions, having a global currency can constrain central banks in pursuing their objectives by limiting the impact of their monetary policy instruments. Krugman (1979), Goldberg and Tille (2008), Rey (2001), Eichengreen et al. (2017), Amiti et al. (2018), Gopinath and Stein (2018), Maggiori et al. (2019), Gourinchas et al. (2019), Ilzetzki et al. (2020), Gopinath et al. (2020) and Bahaj and Reis (2020) study the role of vehicle currencies, international currencies, global currencies and dominant currencies, emphasizing the unit of account function as well as the liquidity role played by securities denominated in these currencies. Gopinath and Stein (2018) justify the dominance of a currency on the basis of a higher share of trade settled in that currency. By contrast, we emphasize the medium of exchange function of money and the direct competition between the national and global currencies in that regard. Financial considerations are, instead, the reason that justifies, in our context, the dominance of a currency through the comparison of return differentials and other asset-pricing relationships. Another contribution of our work with respect to the above-mentioned literature is the analysis of the restrictions imposed by a global currency on international 
financial markets, relating them to the monetary policy followed by the single countries. Along these lines, Ilzetzki et al. (2020) argue that the limited role of the euro in international financial markets can be explained by the policy of the European Central Bank. Benigno (2019) focuses on a one-country model and shows that under competition to cryptocurrencies, the central bank can face some restrictions on interest rates and inflation if the government currency has to retain a role as a medium of exchange. We differ from his analysis by analyzing the consequences of cryptocurrency competition for the international monetary system by building on a general stochastic framework.

Our paper is closely related to the literature on currency competition, currency substitution and dollarization, Classic contributions are by Girton and Roper (1981), who consider the impact of currency substitution on exchange rates, Giovannini and Turtelboom (1992), who examine various consequences of currency substitution, Matsuyama et al. (1993), who consider currency substitution in a two-country, two-currency model of random matching, the exchange rate indeterminacy result due to Kareken and Wallace (1981), and its stochastic version by Manuelli and Peck (1990). Uribe (1997) and Valev (2010) argue that currency substitution shows hysteresis and persistence due to network externalities. Schmitt-Grohé and Uribe (2000) examine currency substitution and their costs. Some of these insights have found a modern echo in the emerging literature on cryptocurrencies. Berentsen (1998) is an early example. Garratt and Wallace (2018) provide an extension of Kareken and Wallace (1981) to cryptocurrencies. Schilling and Uhlig (2019a) focus on implications of competition between a cryptocurrency and traditional fiat money, while Schilling and Uhlig (2019b) analyze the implications of goodsspecific transaction costs. Fernández-Villaverde and Sanches (2019) and Chiu and Koeppl (2019) analyze currency competition and monetary policy in a Lagos-Wright model. Our framework is considerably more general than all these contributions, allowing for interest-bearing bonds and nesting a number of classic monetary models. Our paper is close in spirit to Chahrour and Valchev (2019), who likewise emphasize the importance of an international medium of exchange. Brunnermeier and Niepelt (2019) pursue the implica- 
tions of the equivalence between private and public money, in units of the same currency, while our emphasis is on the international context, on different currencies and, thus, has a different focus. Alesina and Barro (2001), Amiti et al. (2018), Maggiori et al. (2019), Gopinath et al. (2020), Bocola and Lorenzoni (2020), Christiano et al. (2021) and Uhlig and Xie (2021) concern the "unit of account" function of money, i.e. the pricing currency for firms and financial contracts, which is outside of the focus here. Edwards and Magendzo (2003) and recently Ju (2020) have examined the impact of currency substitution on economic performance.

Finally, we contribute to the monetary economics literature examining the role of money as medium of exchange. There are a variety of benchmark approaches that discuss a role of money, see, e.g., Walsh (2010) for an excellent textbook treatment. We take up several of these approaches in Section 7. Concerning the role of money as medium of exchange, the New Monetarist framework developed by Lagos and Wright (2005) has become the benchmark and has spawned a considerable literature. Lagos et al. (2017) provide an excellent survey and assessment. Among recent contributions, Fernández-Villaverde and Sanches (2019) and Chiu and Koeppl (2019) employ the Lagos-Wright framework to analyze currency competition and cryptocurrencies. For our general and minimalistic framework, we abstract from the details of how money is used as a medium of exchange. All that we require is money offering "liquidity services". In section 7, we show that many benchmark approaches in the monetary economics literature, amongst others the Lagos-Wright approach, feature such liquidity services. Thus, the results derived in our abstract and minimalistic structure here apply to a large variety of classic settings.

There, moreover, exists a growing literature that analyze the functionality, feasibility and microincentives of individual cryptocurrencies and blockchain. Biais et al. (2019a,b) analyze equilibria in proof-of-work protocols such as Bitcoin, Chiu and Koeppl (2019) study Bitcoin's suitability as a payment system, Sockin and Xiong (2020) consider strategic complementarities in cryptocurrency investment when currency gives acces to platform services, Ebrahimi et al. (2019) consider robust consensus protocols for blockchain-based dis- 
tributed ledgers, Huberman et al. (2017) analyze revenue generation in the Bitcoin system, Leshno and Strack (2020) characterize Bitcoin as the unique reward scheme that satisfies anonymity, while neither giving incentive for consolidation nor for assuming fake identities, Prat and Walter (2021) use the Bitcoin-Dollar exchange rate for predicting the computing power of the Bitcoin network. Cong and He (2019) analyze implications of decentralized consensus via distributed ledger technology on competition. Garratt and van Oordt (2019) analyze the role of cryptocurrency specific mining equipment for avoiding double spending attacks. This paper abstracts from microincentives and the possibility of attacks, and instead assumes full functionality and reliability of all currencies in this paper.

\section{A simple framework}

This section uses a simplified and non-stochastic framework in order to provide some intuition and to preview the main results of the general framework.

There are two countries, home and foreign, and three currencies: currency $h$ and $f$ in their respective countries and a global (crypto) currency $g$. While currency $h$ can be used for transactions only in country $h$ and the currency $f$ only in country $f$, the global currency can be used in both countries. Money, either in a physical or digital form, provides non-pecuniary benefits, which we call liquidity services and yield liquidity premia. Let us assume that, when

they are both used, the two currencies are perfect substitutes in providing liquidity services.

Let $S_{t}$ be the exchange rate between currency $h$ and $f$ in date t, i.e. the amount of currency $h$ needed to buy one unit of currency $f$. Let $Q_{t}$ denote the amount of currency $h$ needed to buy one unit of the global (crypto) currency. Likewise, let $Q_{t}^{*}$ denote the amount of currency $f$ needed to buy one unit of the global (crypto) currency. Therefore,

$$
Q_{t}=S_{t} Q_{t}^{*}
$$


At a generic time $t$, a resident in country $h$ can acquire $M_{t}$ units in currency $h$ and $G_{t}$ units in the global currency at the exchange rate $Q_{t}$ in terms of home currency, implying an overall expenditure or total money holding

$$
M_{t}^{\text {tot }}=M_{t}+Q_{t} G_{t},
$$

expressed in units of the domestic currency. For the foreign country $f$, we likewise obtain

$$
M_{t}^{* \text { tot }}=M_{t}^{*}+Q_{t}^{*} G_{t}^{*},
$$

where $M_{t}^{*}$ are units in currency $f$ and $G_{t}^{*}$ are units in the global currency held abroad, with the exchange rate $Q_{t}^{*}$ in terms of foreign currency. Note that we are assuming perfect substitutability: the extension to imperfect substitutability is explored in Appendix 6.1. The total stock of global currency is the sum $G_{t}+G_{t}^{*}$, and it can be used in either country. The investor in country $h$ receives non-pecuniary liquidity service benefits from the overall money expenditure $M_{t}^{\text {tot }}$ deflated by the price of some generic consumption good (either tradeable or non-tradeable) for which money is exchanged. At time $t+1$, the two monies deliver an overall payoff $M_{t}+Q_{t+1} G_{t}$, in units of the domestic currency. Since liquidity services provided by each currency are substitutes, the amount of services received is independent of the portfolio choice. Only if the returns on money are equal then agents are willing to hold both currencies in their portfolio. This is equivalent to saying that the exchange rate $Q$ should be constant, $Q_{t+1}=Q_{t}$. Otherwise, one currency would dominate the other as a means of payment. This result is nothing more than a restatement of Kareken and Wallace (1981), additionally allowing the monies to provide liquidity services. The analysis can equivalently be applied to country $f$ to obtain that the exchange rate $Q^{*}$ should also be constant.

Our first result in the paper follows directly from the above analysis: when a global currency is used in both local markets, the exchange rate, $S$, between currency $h$ and $f$ has to be constant too, although $h$ and $f$ do not compete directly since $h$ and $f$ are not simultaneously accepted in the same local market. The monies $h$ and $f$, however, compete indirectly through the global currency 
$g$ which has worldwide acceptance, thereby creating a link between the two local currencies. This indirect competition then enforces equality of returns on $h$ and $f$. To see this result, apply the constancy of $Q$ and $Q^{*}$ into (1).

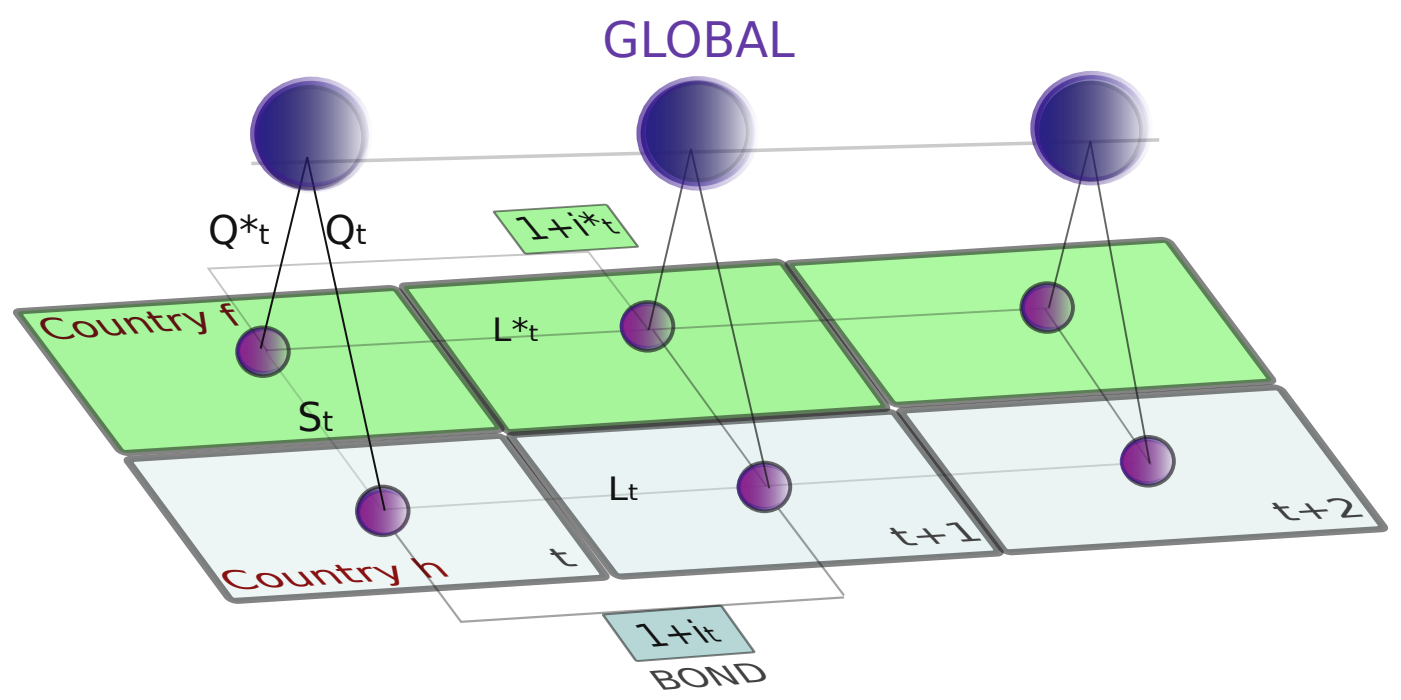

Figure 1: International trade and money flow in time

Our second result states that simultaneous trade in global and local currencies requires the synchronization of monetary policies across countries, i.e., the nominal interest rates are equalized across countries. To see this result, we allow investors in each country to trade also in two nominal bonds denominated in currency $h$ and $f$, respectively. In a non-stochastic economy, with frictionless capital markets, uncovered interest rate parity holds

$$
\frac{1+i_{t}}{1+i_{t}^{*}}=\frac{S_{t+1}}{S_{t}}
$$

in which $i_{t}$ and $i_{t}^{*}$ denote, respectively, the nominal interest rate in country $h$ and $f$ from period $t$ to $t+1$ on one-period bonds denominated in the respective currencies. Since the exchange rate $S$ is constant, interest rates should be equal. Figure 1 summarizes the key relationship between interest rates and exchange rates.

As the next section will show, the result of equal nominal interest rates extends unchanged to a stochastic economy in the case where liquidity services 
of money are delivered at the same time money is held in the portfolio. The result of constant exchange rates generalizes to a stochastic economy with the qualification that the exchange rate between currency $h$ and $f$ follows instead a martingale when adjusting for risk, i.e. in the risk-neutral probability measure. In the stochastic setting, we will further show the equalization of the liquidity premia of money across countries. ${ }^{1}$

Before turning to the more general framework, we discuss here which type of global currency is captured by our analysis. The emphasis is on cryptocurrencies, which are unlinked from any sovereign entity and could be worldwide adopted as medium of exchange rate. Any other currency, even sovereign one, could fit our framework if adopted in many countries. The global currency of our model can be in the form of digital or physical cash. As such, if adopted, it should provide similar liquidity services to the local currencies when competing in their markets. In particular, we think that perfect substitution captures in a better way the challenges of a digital, rather than a physical, global currency since, for its digital nature, it can be carried easily across borders and exchanged, to equally compete with local currencies, in all goods markets. We discuss, however, in Section 6.1 how results change with imperfect substitutability and in Section 8 we further discuss the comparison with other means of payments, as gold or dollars. Finally, it can be a purely fiat currency and not necessarily a stable or backed currency. However, In Section 5, we also discuss the implications of competition coming from an asset-backed global currency.

\section{A general framework}

Our general stochastic multi-period framework is minimalistic on purpose, relying only on asset-pricing considerations to derive our key results. Our structure is broad enough to encompass a large variety of models and approaches of the monetary economics literature, see Section 7. There are two countries

\footnotetext{
${ }^{1}$ Liquidity premia are in general monotone in the opportunity cost of holding money, i.e. the interest rate. Equal interest rates directly imply equal liquidity premia.
} 
$h$ and $f$, each with their own home currency and a safe one-period nominal bond. There is also a global currency $g$. Agents in both countries can trade both bonds and can hold the global currency. The agent in country $h$ can, in addition, hold currency $h$ but not currency $f$. Vice versa, the agent in country $f$ can hold currency $f$ but not currency $h$. An important feature of our model is that whether a currency is used or not is an endogenous choice, depending on the monetary policy of the issuer and on the exchange rate between currencies.

The key assumption for obtaining our result is that markets are complete ${ }^{2}$, arbitrage-free and frictionless. As a consequence, a stochastic discount factor exists and is unique. Let $\mathcal{M}_{t+1}$ denote the nominal stochastic discount factor in units of currency $h$ for the agent in country $h$, and likewise let $\mathcal{M}_{t+1}^{*}$ denote the nominal stochastic discount factor in units of currency $f$ for the agent in country $f$. An implication of complete markets is that the nominal discount factors in units of the two local currencies are connected through their exchange rate since they are equalized once expressed in the same unit of account. ${ }^{3}$

Assumption 3.1 (Complete Markets:).

$$
\mathcal{M}_{t+1}=\mathcal{M}_{t+1}^{*} \frac{S_{t}}{S_{t+1}} \text {. }
$$

Consider a (non-monetary) asset offering a (possibly random) nominal return $R_{t+1}$ in currency $h$. Since returns have a price of one (Cochrane, 2009), the indifference condition of an intertemporal utility maximizing agent implies the following standard asset pricing equation to value a random return $R_{t+1}$,

$$
1=E_{t}\left[\mathcal{M}_{t+1} R_{t+1}\right]
$$

where $\mathcal{M}_{t+1}$ denotes the nominal stochastic discount factor. Thus, since a

\footnotetext{
${ }^{2}$ The assumption can be weakened slightly, but would make the presentation more opaque.

${ }^{3}$ For the generality of this result see Obstfeld (2007).
} 
nominal one-period bond in country $h$ pays a return $R_{t+1}=1+i_{t}$,

$$
\frac{1}{1+i_{t}}=E_{t}\left[\mathcal{M}_{t+1}\right]
$$

and likewise for the bond in country $f$

$$
\frac{1}{1+i_{t}^{*}}=E_{t}\left[\mathcal{M}_{t+1}^{*}\right]
$$

Bonds and currencies are used for the intertemporal transfer of resources. Money needs to offer some liquidity services beyond the intertemporal transfer to be able to compete with interest-bearing bonds for investors. We shall therefore assume that, when used, currency $h$, as well as the global currency, pays a non-monetary liquidity service $L_{t}$ to agents in country $h$ per unit of currency, in addition to the intertemporal payoff. Note that, in our framework, a currency provides liquidity only when it is used, and that its usage is an endogenous choice. Likewise, we assume that currency $f$ pays a liquidity premium $L_{t}^{*}$ to agents in country $f$ per unit of currency. For clarity and simplicity, we assume here that currency $h$ and $g$ in country $h$, as well as currency $f$ and $g$ in country $f$, are perfect substitutes. A detailed generalization and discussion of the case of imperfect substitutability is given in Section 6.1.

In a full model specification such as given in Section 7 , these liquidity services are endogenously determined through optimal consumption choices of households under, for instance, cash-in advance constraints or money-in-theutility function. In all of these models, money is held across periods from $t$ to $t+1$, and the particular model structure determines whether the services are rendered in period $t$ ("immediately") or in $t+1$ ("with delay"). For the benchmark case here we assume the former, but return to the latter in Appendix A.1. In contrast, we shall think of nominal interest rates on bonds as exogenously set policy instruments.

Assumption 3.2 (Liquidity immediacy). The purchase of currency $h$ and $g$ in country $h$ at $t$ yields an immediate liquidity premium $L_{t}$ receivable in $t$. Analogously, the time $t$ purchase of currency $f$ and $g$ in country $f$ at $t$ yields 
an immediate liquidity premium $L_{t}^{*}$ receivable in $t$.

The date- $t$ (post-liquidity) price of a unit of currency $h$, expressed in units of the same currency equals unity, by definition. Standard asset pricing considerations then deliver

$$
1 \geq L_{t}+E_{t}\left[\mathcal{M}_{t+1}\right] .
$$

Whenever (9) holds with equality, agents in country $h$ are willing to accept currency $h$ at its unitary price, since they are exactly compensated by the liquidity premium plus the discounted future value of the payoff, see terms on the right hand side of equation (9). In case of a strict inequality, the current price of currency $h$ is too high compared to the expectations on future price developments such that agents are not willing to hold or purchase the currency. Note that we do not allow for short sale.

If a national currency is accepted, then liquidity services provided by this currency stand in a one-to-one relationship with the nominal interest rate paid on bonds, compare (9) to (7), because the nominal interest is the opportunity cost of holding money for transaction purposes. Likewise, for a unit of the global (or crypto) currency, trading at a price of $Q_{t}$ in terms of units of currency $h$, we obtain

$$
Q_{t} \geq L_{t} Q_{t}+E_{t}\left[\mathcal{M}_{t+1} Q_{t+1}\right],
$$

where this equation holds with equality, if the global currency is used in country $h$, i.e. if agents are compensated for the price $Q_{t}$ of a global currency exactly by the liquidity premium plus the discounted future value of the payoff, on the right hand side of equation (10). The price cannot be lower than the right hand side, since otherwise agents in country $h$ would seek to acquire the currency and bid up its value. The price can be higher, however, if the global currency is not used in country $h$. We implicitly rule out short sales or, more precisely, rule out that short-sold currencies render negative liquidity premia. Combining (7) and (9), we obtain

$$
\frac{i_{t}}{1+i_{t}} \geq L_{t},
$$


which holds with equality when currency $h$ is used and therefore describes a monotone relationship between the nominal interest rate and the liquidity services.

$$
\begin{aligned}
1 & \geq L_{t}^{*}+E_{t}\left[\mathcal{M}_{t+1}^{*}\right] \\
Q_{t}^{*} & \geq L_{t}^{*} Q_{t}^{*}+E_{t}\left[\mathcal{M}_{t+1}^{*} Q_{t+1}^{*}\right], \\
\frac{i_{t}^{*}}{1+i_{t}^{*}} & \geq L_{t}^{*} .
\end{aligned}
$$

In the analysis that follows we stick to the following assumption.

Assumption 3.3 (Non-negative liquidity premia). The liquidity premia are non-negative, i.e. $L_{t} \geq 0$ and $L_{t}^{*} \geq 0$.

This assumption, together with equations (11) and (14), implies that $i_{t} \geq 0$ and $i_{t}^{*} \geq 0$, i.e., imply a zero lower bound for nominal interest rates. Moreover, we assume that at least one currency is used in each country while bonds cannot serve as medium of exchange. ${ }^{4}$

Assumption 3.4 (Currency usage). In each country, at least one currency is used. That is, in country $h$, at least one out of inequalities (9) and (10) holds with equality. In country $f$, at least one out of inequalities (12) and (13) holds with equality.

Additionally, it is reasonable to impose that at least one out of (10) or (13) holds with equality, but we are not making use of that restriction. We make the assumption that the global currency has a positive value in the time period $t$ under consideration.

Assumption 3.5 (Global currency is valued).

$$
Q_{t}>0 \text { and } Q_{t}^{*}>0
$$

Given the triangular relationship among exchange rates, $Q_{t}=S_{t} Q_{t}^{*}$, it follows that $Q_{t}>0$ if and only if $Q_{t}^{*}>0$. Thus, the currency being valued in

\footnotetext{
${ }^{4}$ We abstract from the issue of existence of non-monetary equilibria, which naturally arises in monetary models of fiat money.
} 
one country necessarily spills over to the other country.

Some additional terminology shall prove useful. For a generic random variable $X_{t+1}$, define the risk adjusted expectation $\tilde{E}_{t}\left[X_{t+1}\right]$ in country $h$ as

$$
\tilde{E}_{t}\left[X_{t+1}\right] \equiv \frac{E_{t}\left[\mathcal{M}_{t+1} X_{t+1}\right]}{E_{t}\left[\mathcal{M}_{t+1}\right]},
$$

and the risk adjusted expectation $\tilde{E}_{t}^{*}\left[X_{t+1}\right]$ in country $f$ as

$$
\tilde{E}_{t}^{*}\left[X_{t+1}\right] \equiv \frac{E_{t}\left[\mathcal{M}_{t+1}^{*} X_{t+1}\right]}{E_{t}\left[\mathcal{M}_{t+1}^{*}\right]}
$$

As a consequence of market completeness and bond pricing, (5), (7) and (8), we obtain uncovered interest parity (UIP), when using the risk-adjusted measure or risk neutral probability distribution,

$$
\begin{aligned}
\frac{\tilde{E}_{t}\left[S_{t+1}\right]}{S_{t}} & =\frac{1+i_{t}}{1+i_{t}^{*}} \\
\frac{\tilde{E}_{t}^{*}\left[S_{t+1}^{*}\right]}{S_{t}^{*}} & =\frac{1+i_{t}^{*}}{1+i_{t}}
\end{aligned}
$$

where $S_{t}^{*}=1 / S_{t}$. Note that UIP holds irrespective of whether there is a global currency or not. UIP and the associated risk premia have received considerable attention in the literature, see e.g. Engel (2016). Here we obtain it as a consequence of free capital markets.

\section{Main Results}

Proposition 4.1 (Stochastic Economy under Liquidity Immediacy)

Assume liquidity immediacy, complete markets, and that the global currency is valued. If all currencies are used in both countries, i.e. if equations (9), (10), (12) and (13) hold with equality, then

1. the nominal interest rates are equalized $i_{t}=i_{t}^{*}$;

2. the liquidity premia are equal $L_{t}=L_{t}^{*}$; 
3. the nominal exchange rate $S_{t}$ between currency $h$ and $f$ follows a martingale, using risk adjusted expectations of country $h$;

4. the nominal exchange rate $S_{t}^{*}=1 / S_{t}$ between currency $f$ and $h$ follows a martingale, using risk adjusted expectations of country $f$.

Proof. [Proposition 4.1] The competition between currency $h$ and the global currency, i.e. (9) and (10) with equality, the complete-market assumption (5) and finally the competition between currency $f$ and the global currency, i.e. (12) and (13) with equality, deliver

$$
E_{t}\left[\mathcal{M}_{t+1}\right]=E_{t}\left[\mathcal{M}_{t+1} \frac{Q_{t+1}}{Q_{t}}\right]=E_{t}\left[\mathcal{M}_{t+1}^{*} \frac{Q_{t+1}^{*}}{Q_{t}^{*}}\right]=E_{t}\left[\mathcal{M}_{t+1}^{*}\right]
$$

Equations (9) and (12) now imply $L_{t}=L_{t}^{*}$ and thus $i_{t}=i_{t}^{*}$, per equations (11) and (14). The martingale properties of the exchange rate follow from equations (18) and (19) together with $i_{t}=i_{t}^{*}$.

Proposition 4.1 says that, with complete markets, global usage of the global currency, and simultaneous usage of the local currency, monetary policies must be perfectly synchronized. But does Proposition 4.1 mean that the central banks in the two countries have no choice but to accept this fate of coordinated monetary policy? When central banks in Home and Foreign are independent, they can set their interest rates distinctly from one another. Proposition 4.1 can also be read the other way around. If $i_{t} \neq i_{t}^{*}$, then at least one of the presumptions has to be violated: either the global currency is not used in at least one country or one of the national currencies is not in use or both. The central bank in country $h$ may then contemplate pursuing a policy that makes sure that the global currency is not used in country $h$, i.e. that (10) remains an inequality.

Proposition 4.2 (Escaping global currency adoption)

Assume liquidity immediacy, complete markets, and that the global currency is valued. Assume that both local currencies are used in their corresponding 
countries, i.e. equations (9) and (12) hold with equality. Independently of whether the global currency is used or not in country $f$, if $i_{t}<i_{t}^{*}$, then

1. the global currency is not adopted in country $h$;

2. the liquidity premia satisfy $L_{t}<L_{t}^{*}$;

3. the nominal exchange rate $S_{t}$ between currency $h$ and $f$ follows a supermartingale, using risk adjusted expectations in country $h$;

4. the nominal exchange rate $S_{t}^{*}=1 / S_{t}$ between currency $f$ and $h$ follows a submartingale, using risk adjusted expectations in country $f$.

The proof is in appendix A.1. To understand the economics behind this result, it is important to acknowledge not only the competition between the currency $h$ respectively $f$ and the global currency but also the countrywide competition between the bond and currency and the role of the frictionless foreign exchange-rate market. The proof has three parts. First, since the nominal interest rate in country $f$ is higher than the nominal interest rate in country $h$, liquidity services in country $f$ are higher than in country $h$. Second, the competition between the national currencies and the global currency yields upper bounds on the risk-adjusted return of the global currency. The bound is sharper, if the nominal interest rate is higher, i.e. in country $f$, and it binds, if the global currency is adopted. Third, by frictionless foreign exchange-rate markets and the no arbitrage condition, the risk-adjusted return on the global currency has to be equal in countries $h$ and $f$. As a consequence, the country with the weaker constraint on that return does not adopt the global currency.

The proposition shows that there is an escape hatch indeed, but only to one side. Starting from an equilibrium in which the global currency is used in both countries, by lowering the risk-free interest rate in currency $h$ below that in currency $f$, the central bank in country $h$ lowers the opportunity costs of holding the domestic currency and thus makes it more attractive than the global currency as a means of payment, crowding out the global currency in country $h$. Proposition B.1 in the appendix shows that an analogous deterrence-result 
holds in the case of imperfect substitutability of currencies, allowing distinct liquidity services of national and global currency.

This escape hatch is not particularly attractive, however. Nominal interest rates can only be lowered to zero. Furthermore, a rat race between the two central banks may eventually force both to stick to the zero lower bound forever or at low interest rates. ${ }^{5}$ Some may applaud this as the ultimate and global implementation of the Friedman rule, while others may fear deflationary spirals and macroeconomic damage. Either way, these are surely dramatic consequences of the circulation of a global currency.

The next Proposition analyzes the opposite scenario, in which the home central bank raises its rates above the foreign one. When the global currency is used in country $f$, this leads to the abandonment of the home currency as a medium of exchange: presumably an even less attractive option for the home central bank. Our stark result here might be thought of as a version of dollarization going hand-in-hand with high local currency inflation rates or hyperinflations: the latter can perhaps be thought of as a "slo-mo" version of abandoning the currency.

Proposition 4.3 (Losing medium-of-exchange property)

Assume liquidity immediacy, complete markets, and that the global currency is used in country $f$, i.e. equation (13) holding with equality. If the central bank in country $h$ sets $i_{t}>i_{t}^{*}$, then currency $h$ is abandoned in country $h$ and the global currency takes over (currency substitution). Currency $h$ would also be abandoned in country $h$ if the central bank sets $i_{t}=i_{t}^{*}$ and only currency $g$ is used in country $f$.

The proof is in appendix A.2. We call the collection of the three results in Propositions 4.1, 4.2 and 4.3 Crypto-Enforced Monetary Policy Synchronization (CEMPS). They demonstrate that introducing a global currency in

\footnotetext{
${ }^{5}$ In a one-country model Benigno (2019) shows that if the central bank keeps the inflation target below the growth rate of private currency, then it can maintain the monopoly power on the medium of exchange. However, cryptocurrencies' issuance is in general engineered with quite low, or zero, growth rates so that inflation targets set by central banks should be close to zero or below.
} 
a free international capital market constitutes a constraint on the Impossible Trinity. Under free capital flows and without a global currency, uncovered interest parity and the classic Impossible Trinity result provides the home central bank with a choice: it can give up on either a pegged exchange rate or monetary policy independence. Our result shows that introducing a global currency implies a further restriction, when it becomes a perfect substitute for the local currencies. Either the monetary policy of the central banks can no longer be independent or central banks risk the crowding out of their own currency. Additionally, the exchange rate is now a risk-adjusted martingale and not necessarily a peg, see also Manuelli and Peck (1990) and Schilling and Uhlig (2019a). The classical Impossible Trinity thus becomes even less recon-

cilable. With currency substitution, the countries' nominal interest rates are equalized independently of whether the economy is stochastic or deterministic.

To conclude this analysis, it is important to emphasize that the results of this section have abstracted from the monetary policy followed by the issuer of the global currency. This can be characterized by fully developing the different monetary models - all nested in our general framework - that we present in Section 6. In this abstraction, it should be understood that when the global currency is perfect substitute of the local currency, in providing liquidity services, is because of the underlying monetary policy. On the other side, this section has been more explicit on the monetary policy of the local currencies showing that their stance determines their relative value with respect to other currencies and therefore whether they are going to be used as a medium of exchange. In the next section, when we treat the case of an asset-backed global currency, we will instead provide more details on how its issuer can control the value of its currency relative to the local one.

\section{Special case: Asset-backed global currencies}

This section is motivated by the fairly recent proposal by a Facebook-led consortium to launch a new global currency called Diem. While the Diem project itself has undergone considerable changes since its inception as Libra and may 
be scrapped altogether, it is not implausible that a privately issued and globally usable digital currency of widespread use and backed by a basket of assets emerges in the near future. We therefore analyze the consequences of introducing a global currency backed by a basket of risk-free securities denominated in government currencies. In our framework, suppose that the issuing consortium backs the global currency by safe bonds denominated in currency $h$. Moreover, assume that the consortium is ready to buy and sell any amount of the global currency at a fixed price $Q_{t}$. When issuing the amount $\Delta_{t}$ of the global currency at some date $t$, the consortium invests the proceeds $\Delta_{t} Q_{t}$ in the safe bonds of country $h$. In period $t+1$, the consortium receives the interest payments on the bonds. The consortium keeps a portion of the date $t+1$ portfolio value as a per-period asset management fee, assumed to be $\phi_{t} \Delta_{t} Q_{t}$ for some $\phi_{t} \geq 0$ set in $t$. One may wish to think of these fees as profits paid to the shareholders of the consortium. The consortium then sets the new price $Q_{t+1}$, again trading any amount of the global currency at that price and investing their client's funds in home safe bonds. The return that accrues to the global currency between $t$ and $t+1$, i.e., the bond return after applying the management fee, can be redeemed at the global currency's price $Q_{t+1}$ or is reinvested. In order to credibly promise the repurchase of the global currency for a price $Q_{t+1}$ at $t+1$ and assuming no profits beyond the asset management fee, assets and liabilities have to grow at the same rate,

$$
Q_{t+1}=\left(1+i_{t}-\phi_{t}\right) Q_{t}
$$

Note that for $i_{t} \geq \phi_{t}$ the price of the global currency then increases over time $Q_{t+1} \geq Q_{t}$.

Proposition 5.1 (Asset backed global currency)

Assume that the global currency is valued.

1. If $\phi_{t}<i_{t}$, then currency $h$ is crowded out and only the global currency is used in country $h$. Moreover, $L_{t}=\frac{\phi_{t}}{1+i_{t}}$.

2. If $\phi_{t}=i_{t}$, both currency $h$ and the global currency coexist in country $h$. 
3. If $\phi_{t}>i_{t}$, then only currency $h$ is used in country $h$.

The proof is in appendix A.3. From the results in Proposition 5.1, we can generate more striking implications if we assume the fee to apply in the form of a fixed portion of the interest payments, $\phi_{t}=\kappa i_{t}$ for some parameter $0 \leq \kappa \leq 1$. Then

1. If $\kappa<1$, then $i_{t} \leq \phi_{t}$ only holds for $i_{t}=0$. Moreover, $i_{t}=0$ implies $\phi_{t}=0$ and the global currency is used together with the local currency in country $h$.

2. If $\kappa=1$ ( or $\phi_{t}=i_{t}$ ), then the price $Q_{t}$ for the global currency is fixed (Stablecoin) and both currencies are used.

A useful reading of the above results from a central-banking perspective is the following. For local currency $h$ to remain in usage, the nominal interest rate has to undercut or match the management fee $\phi$. The proposition therefore suggests that an interesting Bertrand-type game could unfold. The home central bank may seek to undercut the fee charged by the consortium, in order to drive the global currency out of usage at home. But without usage, the global currency consortium cannot earn any revenue from the fees: it would be better off by lowering its fees in response. ${ }^{6}$ In the limit, this dynamic could result in both parties ratcheting down the "price" for their currencies to their marginal costs of issuance. If these marginal costs are zero or near zero, an assumption often made in the literature, then one obtains a zero interest rate policy and a zero fee. Put differently, currency competition between currency $h$ and the global currency leads to the establishment of the celebrated Friedman rule to keep interest rates at zero, thereby setting the private costs of holding the currencies equal to the social cost of its production. There is a large literature establishing conditions under which the Friedman rule is optimal, see Woodford (1990). More generally, if one currency has higher marginal production costs than the other, then the resulting zero profit condition for

\footnotetext{
${ }^{6}$ The consortium may not care if country $h$ is small. It presumably would care, though, if the country was large and economically important or a large and important currency union.
} 
this higher-cost currency will dictate the resulting limit. From the consortium's perspective, the nominal interest rate on the backing asset provides an upper bound on the fee that can be charged while maintaining usage of the global currency.

These results are also reminiscent of the view in Hayek (1978), that unfettered competition can align private incentives with social objectives. To extract rents from liquidity services, currency issuers have to supply better money than others by keeping its value high and, therefore, inflation low. But then competition kicks in, driving rents to zero and eliminating liquidity premia so that the better money also serves the social benefits. Benigno (2019) presents a model of currency competition obtaining the same result under free entry. Our insights are related to the analysis in Marimon et al. (2003), who likewise emphasize that cheap inside monies place tight upper bounds on inflation rates there or nominal interest rates here.

\section{Robustness}

In this Section, we study the robustness of our results by relaxing two important assumptions we made: 1) the perfect substitutability between the local and the global currency; 2) complete international financial markets.

\subsection{Imperfect substitutability of currencies}

The main model assumes that, within a country, the liquidity services on the national and the global currency are identical. We generalize this feature in this section to allow for imperfect substitutability ${ }^{7}$. This requires a bit more structure and notation. As in Section 2, let $M_{t}^{\text {tot }}$ denote the total money holdings in country $h$ at time $t$, expressed in units of the domestic currency. In Section 2 and implicitly in the general framework of Section 3, we have assumed that total money in a country is the sum of the nominal amount of

\footnotetext{
${ }^{7}$ See also the transaction-costs-based approach in Schilling and Uhlig (2019b) as well as the closely related analysis is in the undergraduate honors thesis by Kei Irizawa, University of Chicago 2020.
} 
the domestic currency as well as the nominal value of the global currency used in the country, see equations (2) and (3). More generally, assume now that

$$
\begin{aligned}
M_{t}^{\mathrm{tot}} & =a\left(M_{t}, Q_{t} G_{t}\right) \\
M_{t}^{*}, \mathrm{tot} & =a\left(M_{t}^{*}, Q_{t}^{*} G_{t}^{*}\right)
\end{aligned}
$$

for some concave, non-negative, twice continuously differentiable constantreturns-to-scale function $a(\cdot, \cdot)$ with strictly positive partial derivatives and with $0=a(0,0)$, aggregating the two money components to the total money stock. For the linear specification $a(m, g)=m+g$, we obtain (2) and (3). A nonlinear $a(\cdot, \cdot)$ captures the idea that the national currency may be relatively more useful for certain transactions, while the global currency is more useful for others. Define the real value of the money stocks as

$m_{t}^{\text {tot }}=\frac{M_{t}^{\text {tot }}}{P_{t}}, m_{t}=\frac{M_{t}}{P_{t}}, g_{t}=\frac{Q_{t} G_{t}}{P_{t}}, m_{t}^{*, \text { tot }}=\frac{M_{t}^{*, \text { tot }}}{P_{t}^{*}}, m_{t}^{*}=\frac{M_{t}^{*}}{P_{t}^{*}}, g_{t}^{*}=\frac{Q_{t}^{*} G_{t}^{*}}{P_{t}^{*}}$.

Due to constant returns to scale, equations (22) and (23) can then alternatively be written as

$$
\begin{aligned}
m_{t}^{\text {tot }} & =a\left(m_{t}, g_{t}\right) \\
m_{t}^{*, \text { tot }} & =a\left(m_{t}^{*}, g_{t}^{*}\right)
\end{aligned}
$$

Assume that the aggregate stock of total real money $m^{\text {tot }}$ provides a benefit $v\left(m^{\text {tot }}\right)$ and assume that $\lambda_{t}$ is the Lagrange multiplier on the nominal date- $t$ budget constraint, where either type of money as well as the bonds are acquired. These assumptions arise directly in a money-in-the-utility formulation as in subsection 7.2, when allowing for the same imperfect substitutability as here. They likewise arise in a Lagos-Wright model as in subsection 7.1 or a cash-in-advance model as in subsection 7.3 with some work. Let $a_{1, t}$ and $a_{2, t}$ denote the partial derivatives $a_{1}\left(m_{t}, g_{t}\right)$ and $a_{2}\left(m_{t}, g_{t}\right)$ of $a$ with respect to the first respectively second argument and evaluated at $m_{t}$ and $g_{t}$. Likewise, let $a_{1, t}^{*}$ and $a_{2, t}^{*}$ denote the partial derivatives $a_{1}\left(m_{t}^{*}, g_{t}^{*}\right)$ and $a_{2}\left(m_{t}^{*}, g_{t}^{*}\right)$ of $a$ with 
respect to the first respectively second argument and evaluated at $m_{t}^{*}$ and $g_{t}^{*}$. The first-order conditions with respect to $M_{t} \geq 0$ and $G_{t} \geq 0$ are

$$
\begin{aligned}
\lambda_{t} & \geq v^{\prime}\left(m_{t}^{\text {tot }}\right) \frac{a_{1, t}}{P_{t}}+\beta E_{t}\left[\lambda_{t+1}\right] \\
Q_{t} \lambda_{t} & \geq v^{\prime}\left(m_{t}^{\text {tot }}\right) \frac{Q_{t} a_{2, t}}{P_{t}}+\beta E_{t}\left[\lambda_{t+1} Q_{t+1}\right]
\end{aligned}
$$

Note that these partial derivatives are identical to one in the linear case (2) and (3). With $\mathcal{M}_{t+1}=\beta \lambda_{t+1} / \lambda_{t}$ and with liquidity services $L_{t}$ of total money defined $^{8}$ as

$$
L_{t}=\frac{v^{\prime}\left(m_{t}^{\mathrm{tot}}\right)}{P_{t} \lambda_{t}}
$$

equations (26) and (27) take the more familiar form

$$
\begin{aligned}
& 1 \geq L_{t} a_{1, t}+E_{t}\left[\mathcal{M}_{t+1}\right] \\
& 1 \geq L_{t} a_{2, t}+E_{t}\left[\mathcal{M}_{t+1} \frac{Q_{t+1}}{Q_{t}}\right]
\end{aligned}
$$

with the partial difference terms $a_{1, t}$ and $a_{2, t}$ generalizing the benchmark perfect-substitutability case. For the foreign country, we have likewise

$$
\begin{aligned}
& 1 \geq L_{t}^{*} a_{1, t}^{*}+E_{t}\left[\mathcal{M}_{t+1}^{*}\right] \\
& 1 \geq L_{t}^{*} a_{2, t}^{*}+E_{t}\left[\mathcal{M}_{t+1}^{*} \frac{Q_{t+1}^{*}}{Q_{t}^{*}}\right]
\end{aligned}
$$

Define $\alpha_{t}=\alpha\left(m_{t}, g_{t}, m_{t}^{*}, g_{t}^{*}\right)$ as

$$
\alpha_{t}=\frac{a_{1, t}}{a_{2, t}} / \frac{a_{1, t}^{*}}{a_{2, t}^{*}}=\frac{a_{1}\left(m_{t}, g_{t}\right)}{a_{2}\left(m_{t}, g_{t}\right)} / \frac{a_{1}\left(m_{t}^{*}, g_{t}^{*}\right)}{a_{2}\left(m_{t}^{*}, g_{t}^{*}\right)}
$$

in $^{9}[0, \infty]$ as the relative marginal rates of currency substitution. Note that $\alpha_{t} \equiv 1$ in the linear benchmark case (2) and (3). We now obtain a generalization of proposition 4.1 .

\footnotetext{
${ }^{8}$ This is similar to (66).

${ }^{9} \mathrm{As}$ is conventional, we tacitly assume that division by $\infty$ results in 0 and vice versa.
} 
Proposition 6.1 (Imperfect currency substitutability)

Given the additional assumptions here, complete markets, $Q_{t}>0, Q_{t}^{*}>0$ and that equations (29), (30),(31), (32) hold with equality,

1. the nominal interest rates satisfy

$$
\frac{i_{t}}{1+i_{t}}=\alpha_{t} \frac{i_{t}^{*}}{1+i_{t}^{*}}
$$

2. the liquidity premia for the global currency are equal: $L_{t} a_{2, t}=L_{t}^{*} a_{2, t}^{*}$.

The proof is in appendix A.4. Note that $\alpha_{t}$ is endogenous and may depend on the choice of the nominal interest rates $i_{t}$ and $i_{t}^{*}$ by the central banks. Thus, (34) is merely an equilibrium relationship and not a constraint on monetary policy. However, equation (34) implies bounds on the interest rates. Suppose that for some $\bar{m}>0$ and $\bar{g}>0$, we have $m_{t} \leq \bar{m}$ and $g_{t} \leq \bar{g}$ in all equilibria. As an example, $\bar{m}=\bar{g}$ would be the lowest upper bound for real transactions in a a cash-in-advance economy. Proceed likewise for the foreign country. Define

$$
\underline{\alpha}=\alpha\left(\bar{m}, 0,0, \bar{g}^{*}\right) \quad \text { and } \quad \bar{\alpha}=\alpha\left(0, \bar{g}, \bar{m}^{*}, 0\right) .
$$

In the benchmark linear case, $\underline{\alpha}=\bar{\alpha}=1$.

Lemma 6.1 (Bounds for $\alpha$ ).

$$
\underline{\alpha} \leq \alpha_{t} \leq \bar{\alpha}
$$

The proof is in appendix A.5. Thus, under the assumptions of proposition 6.1,

$$
\underline{\alpha} \frac{i_{t}^{*}}{1+i_{t}^{*}} \leq \frac{i_{t}}{1+i_{t}} \leq \bar{\alpha} \frac{i_{t}^{*}}{1+i_{t}^{*}}
$$

or

$$
\left(\frac{1+i_{t}^{*}}{\underline{\alpha} i_{t}^{*}}-1\right)^{-1} \leq i_{t} \leq \begin{cases}\left(\frac{1+i_{t}^{*}}{\bar{\alpha} i_{t}^{*}}-1\right)^{-1}, & \text { if } \bar{\alpha} \frac{i_{t}^{*}}{1+i_{t}^{*}}<1 \\ \infty, & \text { if } \bar{\alpha} \frac{i_{t}^{*}}{1+i_{t}^{*}} \geq 1\end{cases}
$$

One can read either equation as a constraint on the domestic monetary policy interest rate $i_{t}$, given the foreign interest rate $i_{t}^{*}$ as well as the two 
bounds $\underline{\alpha}$ and $\bar{\alpha}$ : outside these bounds, the assumptions of proposition 6.1 must be violated. To further clarify this, we generalize proposition 4.3.

Proposition 6.2 (Losing medium-of-exchange property with imperfect currency substitutability)

Given the additional assumptions here and complete markets, $Q_{t}>0, Q_{t}^{*}>0$, if the global currency $g$ and local currency $f$ are used in country $f^{10}$ and if the central bank in country $h$ sets

$$
\frac{i_{t}}{1+i_{t}}>\alpha\left(0, g_{t}, m_{t}^{*}, g_{t}^{*}\right) \frac{i_{t}^{*}}{1+i_{t}^{*}}
$$

then currency $h$ is abandoned in country $h$ and the global currency takes over (currency substitution).

The proof is in appendix A.6. While equation (39) is generally tighter than the right hand side of (37), it requires knowledge of the equilibrium variables $g_{t}, m_{t}^{*}$ and $g_{t}^{*}$. For the benchmark linear specification $a(m, g)=m+g$,

we have $\alpha\left(0, g_{t}, m_{t}^{*}, g_{t}^{*}\right)=1$ and again obtain the result in proposition 4.3 that it is sufficient to raise the interest rate in country $h$ just above that of the foreign country to lose medium-of-exchange properties for currency $h$. Generally, results depend on the functional form of the money aggregator. One interesting implication, though, is that currency $h$ is always abandoned whenever $i_{t}>0$ and $i_{t}^{*}=0$, provided $\alpha\left(0, g_{t}, m_{t}^{*}, g_{t}^{*}\right)$ is finite. The latter requirement, however, cannot be taken for granted as the second part of the following corollary shows.

Corollary 6.1 (Functional forms)

Under the assumptions of Proposition 6.2

1. Suppose that the aggregator functions take the form

$$
a(m, g)=m+g+\psi \frac{m g}{m+g}
$$

\footnotetext{
${ }^{10}$ i.e. equations (31) and (32) hold with equality.
} 
for some $\psi \geq 0$. Then equations (37,38) and proposition 6 .2 hold with

$$
\underline{\alpha}=\frac{1}{(1+\psi)^{2}} \quad \text { and } \quad \bar{\alpha}=(1+\psi)^{2}
$$

for equation (36) as well as

$$
1 \leq \alpha\left(0, g_{t}, m_{t}^{*}, g_{t}^{*}\right)=(1+\psi) \frac{1+\psi\left(s_{t}^{*}\right)^{2}}{1+\psi\left(1-s_{t}^{*}\right)^{2}} \leq \bar{\alpha}
$$

for equation (39), where $s_{t}^{*} \equiv m_{t}^{*} /\left(g_{t}^{*}+m_{t}^{*}\right)$ is the share of the foreign currency in the total value of currencies used abroad.

2. Suppose that the aggregator function is the CES function

$$
a(m, g)=\left(m^{\frac{\eta-1}{\eta}}+\gamma g^{\frac{\eta-1}{\eta}}\right)^{\frac{\eta}{\eta-1}}
$$

where $\eta>0$ is the elasticity of substitution and where $\gamma>0$ is a share parameter. Then

$$
\alpha_{t}=\left(\frac{g_{t}}{m_{t}} / \frac{g_{t}^{*}}{m_{t}^{*}}\right)^{1 / \eta},
$$

Equations (37,38) and proposition 6.2 hold with

$$
\underline{\alpha}=0 \quad \text { and } \quad \alpha\left(0, g_{t}, m_{t}^{*}, g_{t}^{*}\right)=\bar{\alpha}=\infty
$$

for equations (36) and (39), with the exception that $\alpha\left(0, g_{t}, 0, g_{t}^{*}\right)$ is undefined. Holding $m_{t}^{*}, g^{*}$ and $i_{t}^{*}>0$ fixed, equation (34) implies

$$
\frac{g_{t}}{m_{t}} \rightarrow \frac{g_{t}^{*}}{m_{t}^{*}}\left(\frac{1+i_{t}^{*}}{i_{t}^{*}}\right)^{\eta} \text { for } i_{t} \rightarrow \infty,
$$

i.e. the value of the home currency in use does not vanish relative to the value of the global currency in use at home, even as the home nominal interest rate diverges. Conversely $g_{t} / m_{t} \rightarrow 0$ as $i_{t} \rightarrow 0$, i.e. the role of the global currency vanishes as the home interest rate approaches the zero lower bound. 
Proof. Calculate.

The first part of the corollary provides a money aggregator in equation (40) such that the national currency is not essential. Although currencies are imperfect substitutes, a sufficiently high nominal interest rate $i_{t}$ in country $h$ will necessarily lead to abandoning the home currency as a medium of exchange, provided the foreign interest rate $i_{t}^{*}$ or the foreign currency share $s_{t}^{*}$ is sufficiently low. Domestic monetary policy may wish avoid that. This is then a version of the crypto-enforced monetary policy synchronization, though softened by the wriggle room up to the interval $\alpha_{t} \in\left[(1+\psi)^{-2},(1+\psi)^{2}\right]$.

Conversely, if home money is essential, $a_{1}\left(0, g_{t}\right)=\infty$, and if $L_{t}>0$, then the home currency will never be abandoned, no matter what domestic monetary policy does: for any $g_{t} \geq 0$, there is some $m_{t}>0$, so that (29) holds with equality. The CES specification (43) of the second part of the corollary exhibits this special case. There, it is perhaps a bit more surprising, that the domestic home currency will continue to play a sizable role, even if domestic monetary policy $i_{t}$ veers far from the foreign monetary policy $i_{t}^{*}$, provided the latter is not at the zero lower bound, see equation (46).

Monetary policy makers should not take too much comfort in that latter case, however. Money is a means to an end. Payment systems evolve. It is hard to see a priori, why home money ought to be essential. The more easily domestic money can be substituted, the stronger the force for monetary policy synchronization. Pulling the levers of independent domestic monetary policy too much might unleash the market place innovations, which ultimately render home currency superfluous as a means of payment. Central banks would do well to pay attention.

The generalizaton to the case, where each country has its own aggregator function $a$ in equation (22) and $a^{*}$ in equation (23) is straightforward. This allows us to illlustrate what happens, if the relative usefulness of the global currency differs across countries. We do so for the benchmark linear case. We obtain the following version of our main result, i.e. of proposition 4.1. 


\section{Corollary 6.2}

Suppose that the aggregator functions take the linear form

$$
\begin{aligned}
a(m, g) & =m+\xi g \\
a^{*}\left(m^{*}, g^{*}\right) & =m^{*}+\xi^{*} g^{*}
\end{aligned}
$$

for some constants $\xi>0$ and $\xi^{*}>0$. Assume complete markets, $Q_{t}>0$, $Q_{t}^{*}>0$ and that (29, 30,31, 32) all hold with equality. Then

$$
\frac{i_{t}}{1+i_{t}}=\frac{\xi^{*}}{\xi} \frac{i_{t}^{*}}{1+i_{t}^{*}}
$$

The proof is in appendix A.7. In particular, the corollary shows that proposition 4.1 remains unchanged, if $\xi=\xi^{*}>0$, i.e., if the global currency offers liquidity services in proportion to the domestic currencies, and these proportions are the same. A more detailed discussion is provided in appendix B.

\subsection{Incomplete markets}

In this section, we relax the assumption of complete markets, by allowing for imperfect risk sharing at the international level. We put some structure by assuming that in each country households can trade in risk-free nominal bonds denominated in the two local currencies.

Assumption 6.1 (Incomplete markets). Assume that agents in both countries can trade nominal bonds denominated in currency $h$ and $f$. Therefore the following asset-pricing conditions hold

$$
\begin{gathered}
\frac{1}{1+i_{t}}=E_{t}\left[\mathcal{M}_{t+1}\right] \\
\frac{1}{1+i_{t}^{*}}=E_{t}\left[\mathcal{M}_{t+1} \frac{S_{t+1}}{S_{t}}\right]
\end{gathered}
$$

in country $h$ and

$$
\frac{1}{1+i_{t}^{*}}=E_{t}\left[\mathcal{M}_{t+1}^{*}\right]
$$




$$
\frac{1}{1+i_{t}}=E_{t}\left[\mathcal{M}_{t+1}^{*} \frac{S_{t}}{S_{t+1}}\right]
$$

in country $f$.

Given the above assumption, we can prove the following Proposition.

Proposition 6.3 (Incomplete Markets)

Given Assumption 6.1, $Q_{t}>0, Q_{t}^{*}>0$ and that all currencies are used in both countries, i.e. if equations (9), (10) and their foreign-country counterparts hold with equality, then the nominal interest rates satisfy

$$
\frac{1}{1+i_{t}^{*}}=\frac{1}{1+i_{t}}+\operatorname{cov}_{t}\left(\frac{Q_{t+1}}{Q_{t}}, \mathcal{M}_{t+1}^{*} \frac{S_{t}}{S_{t+1}}-\mathcal{M}_{t+1}\right)
$$

The proof is in appendix A.8. Incomplete markets create a departure from our main result of equalization of interest rates in the presence of a global currency. However, this departure is limited since it depends only on a covariance term and, therefore, to a first-order approximation it becomes negligible. The covariance that matters is between the exchange rate of the global currency and the uninsurable risk in international financial markets, captured by the deviation from the complete-market assumption.

With complete markets, a higher interest rate in country $h$ with respect to $f$ was crowding out the home currency for the liquidity role. Here, it would be still consistent with the coexistence of the local currency $h$ with the global currency, provided the covariance in (48) is positive, i.e.

$$
\operatorname{cov}_{t}\left(\frac{Q_{t+1}}{Q_{t}}, \mathcal{M}_{t+1}^{*} \frac{S_{t}}{S_{t+1}}\right)>\operatorname{cov}_{t}\left(\frac{Q_{t+1}}{Q_{t}}, \mathcal{M}_{t+1}\right)
$$

The condition says that the global currency provides better insurance in country in country $f$ rather than $h$, i.e. its h-denominated return $Q(t+1) / Q(t)$ is higher in country $f$ rather than country $h$, when resources are needed there as indicated by $\mathcal{M}_{t+1}^{*} S_{t} / S_{t+1}$ as opposed to the necessities at home indicated by $\mathcal{M}_{t+1}$. In equilibrium, the higher risk premium in $h$ is offset by the lower opportunity cost $i_{t}$ of holding money, see equation (48). 
With the caveat of the milder linkage between nominal interest rates given by (48), we would still get that at relatively higher interest rates the local currency is abandoned as a medium of exchange in its country while, at relatively lower rates, it crowds out the global currency.

\section{$7 \quad$ Examples}

In the previous sections, we presented our results using a general framework with a generic notation for the stochastic discount factors and the liquidity services. We now provide several examples of models which put more structure on preferences and constraints. We consider four different models: 1) a LagosWright monetary model; 2) a money-in-utility function model; 3) a cash-inadvance-constraint model in which the "credit" market opens before the "cash" market; 4) a cash-in-advance-constraint model in which the "cash" market opens before the "credit" market. The first three models can be cast in the framework of Section 3 in which liquidity services are received at the same time money is held in the agents' portfolio. Model 4) deals with the case of delayed liquidity services, which is discussed in its more general form in Appendix A.1.

\subsection{Lagos-Wright model}

We describe the home country: the description of the foreign country is exactly parallel. There are infinitely many periods. Each period has two subperiods. In the morning, there is a centralized market $(\mathrm{CM})$, while there is a decentralized market (DM) in the afternoon. There is a continuum of agents. In the $\mathrm{CM}$ market, all agents meet and trade monies, assets, as well as a morning consumption good enjoyed according to a linear utility function. Denote the morning consumption by $c_{t}$. Negative consumption denotes production. In the decentralized market of the afternoon, agents meet pairwise randomly. Each

agent chooses the quantity $q \geq 0$ of a good they wish to produce, experiencing disutility $-w(q)$ in doing so. We normalize $w(0)=0$. Production of a strictly positive quantity is only useful, if the agent they meet happens to like 
that good. From the perspective of each agent, this happens with probability $\sigma$. In that case, we call the producing agent the "seller", and the other agent the "buyer". We assume that buyers can only trade money against goods in the DM; they cannot use other assets such as bonds. Agents therefore have to decide on the quantities $M_{t}$ and $G_{t}$ of the home and global monies to acquire earlier in the CM to allow trading in the DM. If they do not meet a seller, agents will hold their monies until the $\mathrm{CM}$ in the next period. If they meet a seller, they will make the seller a take-it-or-leave-it offer (TIOLI) of $\left(q_{t}, \tilde{M}_{t}, \tilde{G}_{t}\right)$. That is, the buyer offers to purchase a quantity $q_{t}$ in return for currency amounts $\tilde{M}_{t}$ and $\tilde{G}_{t}$. The seller can either accept or reject that offer. Periods are discounted at rate $\beta$. We assume that aggregate shocks will be drawn at "dawn", before the CM opens. There are no further shocks within a period. Given the stochastic sequence $\left(c_{t}, q_{t}\right)_{t=t_{0}}^{\infty}$ for some agent, with $c_{t} \in \mathbf{R}$ and $q_{t} \geq 0$, a buyer agent enjoys utility

$$
E_{0} \sum_{t=0}^{\infty} \beta^{t}\left(c_{t}+\mathbf{1} \text { "buyer" in }{ }^{u}\left(q_{t}\right)-\mathbf{1} \text { "seller" in }{ }_{t} w\left(q_{t}\right)\right)
$$

where 1"buyer" in $t$ and 1"seller" in $t$ are indicator functions taking the value 1 or 0 , depending on whether the agent is a buyer resp. a seller in period $t$ in a match with a successful completion of DM trading. Note here that $q_{t}$ is consumption from the perspective of the buyer and production from the perspective of the seller. Let $1 / P_{t}$ be the CM price in terms of the morning good of a unit of home currency. Put differently, one unit of the morning good $\operatorname{costs} P_{t}$ units of the home currency, which is the conventional notation. One unit of the global currency costs $Q_{t}$ units of the home currency in the morning market. We assume that $u^{\prime}(0)=\infty$ and $w^{\prime}(0)<\infty$ : this assures that buyers and sellers will strike a deal at a strictly positive quantity $q_{t}>0$. Given the linearity of preferences in $c_{t}$, the nominal stochastic discount factor relevant for pricing assets from one morning to the next is therefore

$$
\mathcal{M}_{t+1}=\beta \frac{P_{t}}{P_{t+1}} .
$$


As usual, a riskless nominal bond will offer a nominal interest rate $i_{t}$, satisfying

$$
1=E_{t}\left[\mathcal{M}_{t+1}\left(1+i_{t}\right)\right]
$$

Consider the decentralized market or DM in $t$ and a seller. For a unit of the home currency, he can buy $1 / P_{t+1}$ morning goods in $t+1$, yielding expected utility $E_{t}\left[\beta / P_{t+1}\right]$ when discounted to the DM. Similarly, a unit of the global currency yields discounted utility $E_{t}\left[\beta Q_{t+1} / P_{t+1}\right]$. The seller is therefore indifferent between rejecting the offer versus accepting to produce $q_{t}$ units of the good for receiving $\tilde{M}_{t}$ units of home currency as well as $\tilde{G}_{t}$ units of the global currency, iff

$$
w\left(q_{t}\right)=E_{t}\left[\beta \frac{1}{P_{t+1}}\right] \tilde{M}_{t}+E_{t}\left[\beta \frac{Q_{t+1}}{P_{t+1}}\right] \tilde{G}_{t} .
$$

The buyer enters the DM, holding $M_{t}$ units of the home currency and $G_{t}$ units of the global currency. He values the remaining currencies after transacting with the seller just as much as the seller values received currencies. The buyer makes a TIOLI offer $\left(q_{t}, \tilde{M}_{t}, \tilde{G}_{t}\right)$, evaluating the tradeoff between purchasing goods now against the opportunity costs of spending tomorrow. The buyer thus solves

$$
\max _{q_{t}, \tilde{M}_{t}, \tilde{G}_{t}} u\left(q_{t}\right)-E_{t}\left[\beta \frac{1}{P_{t+1}}\right] \tilde{M}_{t}-E_{t}\left[\beta \frac{Q_{t+1}}{P_{t+1}}\right] \tilde{G}_{t}
$$

subject to keeping the seller at his indifference point (50) and subject to not spending more cash than is available,

$$
\begin{aligned}
& 0 \leq \tilde{M}_{t} \leq M_{t} \\
& 0 \leq \tilde{G}_{t} \leq G_{t}
\end{aligned}
$$


It is immediately clear that we only need to keep track of the total utility equivalent of available currency and spent currency,

$$
\begin{aligned}
& m_{t}=E_{t}\left[\beta \frac{1}{P_{t+1}}\right] M_{t}+E_{t}\left[\beta \frac{Q_{t+1}}{P_{t+1}}\right] G_{t}, \\
& \tilde{m}_{t}=E_{t}\left[\beta \frac{1}{P_{t+1}}\right] \tilde{M}_{t}+E_{t}\left[\beta \frac{Q_{t+1}}{P_{t+1}}\right] \tilde{G}_{t} .
\end{aligned}
$$

Therefore, the buyer's problem can be written as

$$
\begin{aligned}
v\left(m_{t}\right) \quad= & \max _{q_{t}, \tilde{m}_{t}} u\left(q_{t}\right)-\tilde{m}_{t} \\
\text { s.t. } & w\left(q_{t}\right)=\tilde{m}_{t} \\
& \tilde{m}_{t} \leq m_{t}
\end{aligned}
$$

The solution is

$$
u^{\prime}\left(q_{t}\right)=w^{\prime}\left(q_{t}\right)
$$

if the currency constraint $\tilde{m}_{t} \leq m_{t}$ is slack and

$$
w\left(q_{t}\right)=m_{t}
$$

if not. In that case, the latter equation provides an implicit function $q_{t}=$ $q\left(m_{t}\right)$, and implies

$$
w^{\prime}\left(q_{t}\right) q^{\prime}\left(m_{t}\right)=1 .
$$

Armed with these insights, we see that

$$
v^{\prime}\left(m_{t}\right)=0
$$

if the currency constraint is slack and

$$
v^{\prime}\left(m_{t}\right)=u^{\prime}\left(q\left(m_{t}\right)\right) q^{\prime}\left(m_{t}\right)-1=\frac{u^{\prime}\left(q_{t}\right)}{w^{\prime}\left(q_{t}\right)}-1
$$

if not. With (59), we see that (62) holds, regardless of whether the currency constraint is slack or not. In the CM, the buyer can obtain home currency of 
quantity $M_{t}$ at a utility cost $M_{t} / P_{t}$ and global currency of quantity $G_{t}$ at a utility cost $Q_{t} G_{t} / P_{t}$. We can thus proceed to use the indirect utility function $v(m)$ to formulate the $\mathrm{CM}$ problem for the buyer as maximizing

$$
\begin{aligned}
& -\frac{M_{t}}{P_{t}}-\frac{Q_{t} G_{t}}{P_{t}}+\sigma v\left(E_{t}\left[\beta \frac{1}{P_{t+1}}\right] M_{t}+E_{t}\left[\beta \frac{Q_{t+1}}{P_{t+1}}\right] G_{t}\right) \\
& +\left(E_{t}\left[\beta \frac{1}{P_{t+1}}\right] M_{t}+E_{t}\left[\beta \frac{Q_{t+1}}{P_{t+1}}\right] G_{t}\right)
\end{aligned}
$$

Define

$$
L_{t}=\sigma E_{t}\left[\mathcal{M}_{t+1}\right]\left(\frac{u^{\prime}\left(q_{t}\right)}{w^{\prime}\left(q_{t}\right)}-1\right)
$$

Differentiating (63) with respect to $M_{t}$ as well as $G_{t}$ and exploiting (49) yields the two first order conditions as claimed.

$$
\begin{aligned}
1 & =L_{t}+E_{t}\left[\mathcal{M}_{t+1}\right] \\
Q_{t} & =L_{t} Q_{t}+E_{t}\left[\mathcal{M}_{t+1} Q_{t+1}\right]
\end{aligned}
$$

\subsection{Money-in-the-utility-function model}

The model follows the Sidrauski-Brock framework extended to allow for multiple currencies. Consumers preferences in Home country have the form

$$
E_{t_{0}} \sum_{t=t_{0}}^{\infty} \beta^{t-t_{0}}\left\{U\left(C_{t}\right)+V\left(\frac{M_{t}^{\text {tot }}}{P_{t}}\right)\right\}
$$

where $M_{t}^{\text {tot }}=M_{t}+Q_{t} G_{t}$ as in equation (2), where $\beta$ is the rate of time preferences with $0<\beta<1, C$ is a consumption good and $P$ its price in units of currency $h$. We can also assume more generally that $C$ represents a bundle of goods. Consumers enjoy utility from consumption through a concave function $U(\cdot)$ strictly increasing in $C$ and from real money balances by holding currency $h, M$, and the global currency $G$. The utility $V(\cdot)$ increases weakly in real money balances but may exhibit a satiation point at a finite level of real money balances; $Q_{t}$ is the price of the global currency in units of currency $h$. 
Consistently with the general framework of Section 3, consumers can invest in four securities: $i$ ) a risk-free bond denominated in currency $h, B_{h}$, paying an interest rate $i ; i i)$ a risk-free bond denominated in currency $f, B_{f}$, paying an interest rate $i^{*} ;$ iii) nonnegative amounts of money $M \geq 0$ in units of currency $h$ and $i v$ ) nonnegative amounts $G \geq 0$ of the global money. Consumers can also trade in a complete set of state-contingent securities, spanning all states of nature. We omit these securities from the presentation of the consumer's budget constraint. The nominal exchange rate between currency $h$ and $f$ is denoted by $S$, as in the main text; let $T$ denote lump-sum transfers received from the government in units of currency $h$ while $T_{g}$ are the transfers from the issuer of global money in units of the global currency. Finally, $Y$ is the home endowment of good $C$. Preferences in country $f$ are specular, with appropriate starred variables. Consumers are subject to the following budget constraint and wealth process

$$
\begin{aligned}
& B_{h, t}+S_{t} B_{f, t}+M_{t}+Q_{t} G_{t}=W_{t}+P_{t}\left(Y_{t}-C_{t}\right)+T_{t}+Q_{t} T_{g, t}, \\
& W_{t} \equiv M_{t-1}+Q_{t} G_{t-1}+\left(1+i_{t-1}\right) B_{h, t-1}+\left(1+i_{t-1}^{*}\right) S_{t} B_{f, t-1} .
\end{aligned}
$$

In the preferences (65) domestic and global monies are perfect substitutes. Note that our general model in appendix section 6.1 also allows for imperfect substitutability. While we allow the short sales of bonds, as in the main text, we impose a short-sale constraint on the global currency and currency $h$, i.e. $G \geq 0$ and $M \geq 0$. The first-order conditions with respect to $B_{h}, B_{f}, M, G$ are

$$
\begin{gathered}
\frac{U_{C}\left(C_{t}\right)}{P_{t}} \frac{1}{1+i_{t}}=E_{t}\left\{\beta \frac{U_{C}\left(C_{t+1}\right)}{P_{t+1}}\right\} \\
\frac{U_{C}\left(C_{t}\right)}{P_{t}} \frac{1}{1+i_{t}^{*}}=E_{t}\left\{\beta \frac{U_{C}\left(C_{t+1}\right)}{P_{t+1}} \frac{S_{t+1}}{S_{t}}\right\} \\
\frac{U_{C}\left(C_{t}\right)}{P_{t}} \geq \frac{1}{P_{t}} V_{m}\left(\frac{M_{t}^{\mathrm{tot}}}{P_{t}}\right)+E_{t}\left\{\beta \frac{U_{C}\left(C_{t+1}\right)}{P_{t+1}}\right\}
\end{gathered}
$$




$$
\frac{Q_{t} U_{C}\left(C_{t}\right)}{P_{t}} \geq \frac{Q_{t}}{P_{t}} V_{m}\left(\frac{M_{t}^{\text {tot }}}{P_{t}}\right)+E_{t}\left\{\beta \frac{Q_{t+1} U_{C}\left(C_{t+1}\right)}{P_{t+1}}\right\},
$$

with the last two equations holding with equality for an interior solution in which $M \geq 0$ and $G \geq 0$, respectively. As in the main text, at least one should hold with equality. In the above conditions, $U_{C}(\cdot)$ and $V_{m}(\cdot)$ are the partial derivatives of the respective functions. These equations can be cast in the notation of Section 3 by noting that the stochastic discount factors are

$$
\mathcal{M}_{t+1}=\beta \frac{U_{C}\left(C_{t+1}\right)}{U_{C}\left(C_{t}\right)} \frac{P_{t}}{P_{t+1}} \quad \mathcal{M}_{t+1}^{*}=\beta \frac{U_{C}\left(C_{t+1}^{*}\right)}{U_{C}\left(C_{t}^{*}\right)} \frac{P_{t}^{*}}{P_{t+1}^{*}}
$$

and the liquidity premia are

$$
L_{t}=\frac{V_{m}\left(\frac{M_{t}^{\text {tot }}}{P_{t}}\right)}{U_{C}\left(C_{t}\right)} \text { and } L_{t}^{*}=\frac{V_{m}\left(\frac{M_{t}^{*}, \text { tot }}{P_{t}^{*}}\right)}{U_{C}\left(C_{t}^{*}\right)}
$$

where $M_{t}^{* \text {,tot }}$ is defined in (3). Note that liquidity services endogenously satisfy additivity and immediacy. Note that complete markets imply that

$$
\frac{U_{C}\left(C_{t}\right)}{P_{t}}=k \frac{U_{C}\left(C_{t}^{*}\right)}{S_{t} P_{t}^{*}}
$$

for some positive parameter $k$. In the case where purchasing power parity holds, $P_{t}=S_{t} P_{t}^{*}$, marginal utilities of consumption are proportional across countries. When all currencies are used, Proposition 4.1 applies and therefore $L_{t}=L_{t}^{*}$. Another implication is that the marginal utilities of real money balances $V_{m}(\cdot)$ are equalized across countries.

\subsection{Cash-in-advance model, type I}

Consider a cash-in-advance model with the timing of Lucas and Stokey (1987), in which the "credit" market opens before the "cash" market. Consumers living 
in country $h$ have the following preferences

$$
E_{t_{0}} \sum_{t=t_{0}}^{\infty} \beta^{t-t_{0}} U\left(C_{T, t}, C_{N, t}\right)
$$

in which $C_{T}$ and $C_{N}$ are, respectively, a traded and non-traded good and $\beta$, with $0<\beta<1$, is the intertemporal discount factor; $U(\cdot, \cdot)$ is a concave function, strictly increasing in both arguments. Preferences in country $f$ are similar with variables denoted by a star. Each period is divided into two subperiods. In the first sub-period financial markets are open and the consumer's budget constraint is given by

$$
B_{h, t}+S_{t} B_{f, t}+M_{t}+Q_{t} G_{t}=W_{t}+T_{t}+Q_{t} T_{g, t}
$$

in which $W_{t}$ is the nominal wealth, which remains after taking into account the purchases of goods in the previous period

$$
\begin{aligned}
W_{t}= & \left(1+i_{t-1}\right) B_{h, t-1}+\left(1+i_{t-1}^{*}\right) S_{t} B_{f, t-1}+M_{t-1}+Q_{t} G_{t-1}+ \\
& +P_{T, t-1}\left(Y_{T, t-1}-C_{T, t-1}\right)+P_{N, t-1}\left(Y_{N, t-1}-C_{N, t-1}\right) .
\end{aligned}
$$

$Y_{T}$ and $Y_{N}$ are the endowments of the traded and non-traded goods, and $P_{T}$ and $P_{N}$ the respective prices. In the second subperiod of period $t$, the "cash" market opens and non-traded goods can be purchased following this constraint

$$
M_{t}^{\text {tot }} \geq P_{N, t} C_{N, t}
$$

where $M_{t}^{\text {tot }}=M_{t}+Q_{t} G_{t}$ as in equation (2). Budget constraints can be written specularly for the consumers living in country $f$.

The first-order conditions with respect to $B_{h}, B_{f}, M, G$ are

$$
\begin{gathered}
\frac{\lambda_{t}}{1+i_{t}}=E_{t}\left\{\beta \lambda_{t+1}\right\} \\
\frac{\lambda_{t}}{1+i_{t}^{*}}=E_{t}\left\{\beta \lambda_{t+1} \frac{S_{t+1}}{S_{t}}\right\}
\end{gathered}
$$




$$
\begin{gathered}
\lambda_{t} \geq \mu_{t}+\beta E_{t}\left\{\lambda_{t+1}\right\} \\
\lambda_{t} Q_{t} \geq \mu_{t} Q_{t}+\beta E_{t}\left\{\lambda_{t+1} Q_{t+1}\right\}
\end{gathered}
$$

with the last two equations holding with equality for an interior solution $M_{t}>$ 0 and $G_{t}>0$, respectively; $\lambda_{t}$ and $\mu_{t}$ are the multipliers associated with constraints (68) and (70), respectively. Moreover, the first-order conditions with respect to $C_{N}$ and $C_{T}$ imply that

$$
\begin{gathered}
\frac{U_{C_{N}}\left(C_{T, t}, C_{N, t}\right)}{P_{N, t}}=\mu_{t}+\beta E_{t}\left\{\lambda_{t+1}\right\}, \\
\frac{U_{C_{T}}\left(C_{T, t}, C_{N, t}\right)}{P_{T, t}}=\beta E_{t}\left\{\lambda_{t+1}\right\},
\end{gathered}
$$

where $U_{C_{T}}(\cdot, \cdot)$ and $U_{C_{N}}(\cdot, \cdot)$ are the derivatives of function $U(\cdot, \cdot)$ with respect to the first and second arguments, respectively. We can now map this model in the notation of the general framework of Section 3 by noting that the stochastic discount factors are given by

$$
\mathcal{M}_{t+1}=\frac{\beta \lambda_{t+1}}{\lambda_{t}} \quad \mathcal{M}_{t+1}^{*}=\frac{\beta \lambda_{t+1}^{*}}{\lambda_{t}^{*}}
$$

while the liquidity premia can be written instead as

$$
L_{t}=\frac{\mu_{t}}{\lambda_{t}} \quad L_{t}^{*}=\frac{\mu_{t}^{*}}{\lambda_{t}^{*}} .
$$

Using first-order conditions (73), (75) and (76), we can also write the nominal stochastic discount factors

$$
\begin{aligned}
\mathcal{M}_{t+1} & =\beta \frac{U_{C_{N}}\left(C_{T, t+1}, C_{N, t+1}\right)}{U_{C_{N}}\left(C_{T, t}, C_{N, t}\right)} \frac{P_{N, t}}{P_{N, t+1}} \\
\mathcal{M}_{t+1}^{*} & =\beta \frac{U_{C_{N}}\left(C_{T, t+1}^{*}, C_{N, t+1}^{*}\right)}{U_{C_{N}}\left(C_{T, t}^{*}, C_{N, t}^{*}\right)} \frac{P_{N, t}^{*}}{P_{N, t+1}^{*}}
\end{aligned}
$$


and the liquidity premia as

$$
\begin{aligned}
L_{t} & =\frac{U_{C_{N}}\left(C_{T, t}, C_{N, t}\right)-\frac{P_{N, t}}{P_{T, t}} U_{C_{T}}\left(C_{T, t}, C_{N, t}\right)}{U_{C_{N}}\left(C_{T, t}, C_{N, t}\right)} \\
L_{t}^{*} & =\frac{U_{C_{N}}\left(C_{T, t}^{*}, C_{N, t}^{*}\right)-\frac{P_{N, t}}{P_{T, t}} U_{C_{T}}\left(C_{T, t}^{*}, C_{N, t}^{*}\right)}{U_{C_{N}}\left(C_{T, t}^{*}, C_{N, t}^{*}\right)} .
\end{aligned}
$$

As in the case of money-in-the-utility function, liquidity services endogenously satisfy additivity and immediacy. The results of Proposition 4.1 apply in the case that all currencies are used. Additional results can be derived in this particular example. Note first that market completeness implies that $\lambda_{t}=\kappa \lambda_{t}^{*}$ for some positive constant $\kappa$ and at all $t$, which in the context of the above model can also be written as

$$
\frac{U_{C_{N}}\left(C_{T, t}, Y_{N, t}\right)}{P_{N, t}}=k \frac{U_{C_{N}}\left(C_{T, t}^{*}, Y_{N, t}^{*}\right)}{S_{t} P_{N, t}^{*}}
$$

Under appropriate assumptions on the initial distribution of wealth, the constant $k$ can be set equal to $1 .^{11}$ In $(77)$, we have substituted equilibrium in the non-traded goods market, $C_{N, t}=Y_{N, t}$ and $C_{N, t}^{*}=Y_{N, t}^{*}$. Moreover, combining first-order conditions (71), (73), (75) and (76) it is possible to obtain that

$$
\frac{U_{C_{N}}\left(C_{T, t}, Y_{N, t}\right)}{U_{C_{T}}\left(C_{T, t}, Y_{N, t}\right)}=\left(1+i_{t}\right) \frac{P_{N, t}}{P_{T, t}} \quad \frac{U_{C_{N}}\left(C_{T, t}^{*}, Y_{N, t}^{*}\right)}{U_{C_{T}}\left(C_{T, t}^{*}, Y_{N, t}^{*}\right)}=\left(1+i_{t}^{*}\right) \frac{P_{N, t}^{*}}{P_{T, t}^{*}},
$$

Using $i_{t}=i_{t}^{*}$ and (77) with $k=1$ in the above conditions, we obtain that

$$
\frac{U_{C_{T}}\left(C_{T, t}, Y_{N, t}\right)}{U_{C_{T}}\left(C_{T, t}^{*}, Y_{N, t}^{*}\right)}=\frac{P_{T, t}}{S_{t} P_{T, t}^{*}}
$$

Assume that the law-of-one price holds for traded goods, $P_{T, t}=S_{t} P_{T, t}^{*}$, and consider the special case in which $Y_{N, t}=Y_{N, t}^{*}$. Then (78) implies perfect crosscountry risk-sharing of the consumption of traded goods, $C_{T, t}=C_{T, t}^{*}$. Using

\footnotetext{
${ }^{11}$ The result that $\lambda_{t}=\kappa \lambda_{t}^{*}$ implies (77) is driven by the fact that money allows the insurance of any movement in the price of non-traded goods in the cash constraint (70).
} 
this result in (77), we also obtain that the law-of-one price holds for non-traded goods $P_{N, t}=S_{t} P_{N, t}^{*}$, for which the equalization of the nominal interest rates is key.

\subsection{Cash-in-advance model, type II}

Consider a cash-in-advance model with a different timing, in which the "cash" market now opens before the "credit" market. Preferences of consumers living in country $h$ are similar to (67). Each period is divided into two sub-periods. In the first sub-period the non-traded good can be purchased subject to the following constraint,

$$
M_{t-1}+Q_{t} G_{t-1} \geq P_{N, t} C_{N, t}
$$

in which variables follow previous definitions. After the "cash" market closes, in the second sub-period of period $t$ the "credit" market opens and consumers are subject to the following constraint,

$$
\begin{gathered}
B_{h, t}+S_{t} B_{f, t}+M_{t}+Q_{t} G_{t}+P_{T, t} C_{T, t}+P_{N, t} C_{N, t}= \\
+P_{T, t} Y_{T, t}+P_{N, t} Y_{N, t}+T_{t}+Q_{t} T_{g, t}+W_{t}
\end{gathered}
$$

where

$$
W_{t} \equiv\left(1+i_{t-1}\right) B_{h, t-1}+\left(1+i_{t-1}^{*}\right) S_{t} B_{f, t-1}+M_{t-1}+Q_{t} G_{t-1} .
$$

Budget constraints can be specularly written for the consumers in country $f$. The first-order conditions with respect to $B_{h}, B_{f}, M, G$ are

$$
\begin{gathered}
\frac{\lambda_{t}}{1+i_{t}}=E_{t}\left\{\beta \lambda_{t+1}\right\} \\
\frac{\lambda_{t}}{1+i_{t}^{*}}=E_{t}\left\{\beta \lambda_{t+1} \frac{S_{t+1}}{S_{t}}\right\} \\
\lambda_{t} \geq \beta E_{t}\left\{\mu_{t+1}+\lambda_{t+1}\right\} \\
\lambda_{t} Q_{t} \geq \beta E_{t}\left\{\left(\mu_{t+1}+\lambda_{t+1}\right) Q_{t+1}\right\}
\end{gathered}
$$


with the last two equations holding with equality for an interior solution $M_{t}>0$ and $G_{t}>0$, respectively. In the above conditions, $\lambda_{t}$ and $\mu_{t}$ are the multipliers associated with constraints (80) and (79), respectively. Moreover, the first-order conditions with respect to $C_{N}$ and $C_{T}$ imply that

$$
\begin{gathered}
\frac{U_{C_{N}}\left(C_{T, t}, C_{N, t}\right)}{P_{N, t}}=\mu_{t}+\lambda_{t}, \\
\frac{U_{C_{T}}\left(C_{T, t}, C_{N, t}\right)}{P_{T, t}}=\lambda_{t} .
\end{gathered}
$$

Note that in this model liquidity premia are received with a one-period delay. Therefore, this example can be mapped in the notation of the general framework presented in Appendix A.1 by noting that the stochastic discount factors are given by

$$
\mathcal{M}_{t+1}=\frac{\beta \lambda_{t+1}}{\lambda_{t}} \quad \mathcal{M}_{t+1}^{*}=\frac{\beta \lambda_{t+1}^{*}}{\lambda_{t}^{*}}
$$

while liquidity premia are

$$
L_{t+1}=\frac{\mu_{t+1}}{\lambda_{t+1}} \quad L_{t+1}^{*}=\frac{\mu_{t+1}^{*}}{\lambda_{t+1}^{*}} .
$$

Using first-order conditions (81) and (82), we can further write the stochastic discount factors and the liquidity premia as

$$
\begin{aligned}
& \mathcal{M}_{t+1}=\beta \frac{U_{C_{T}}\left(C_{T, t+1}, C_{N, t+1}\right)}{U_{C_{T}}\left(C_{T, t}, C_{N, t}\right)} \frac{P_{T, t}}{P_{T, t+1}} \\
& \mathcal{M}_{t+1}^{*}=\beta \frac{U_{C_{T}}\left(C_{T, t+1}^{*}, C_{N, t+1}^{*}\right)}{U_{C_{T}}\left(C_{T, t}^{*}, C_{N, t}^{*}\right)} \frac{P_{T, t}^{*}}{P_{T, t+1}^{*}}
\end{aligned}
$$

and

$$
\begin{aligned}
& 1+L_{t+1}=\frac{U_{C_{N}}\left(C_{T, t+1}, C_{N, t+1}\right)}{U_{C_{T}}\left(C_{T, t+1}, C_{N, t+1}\right)} \frac{P_{T, t+1}}{P_{N, t+1}} \\
& 1+L_{t+1}^{*}=\frac{U_{C_{N}}\left(C_{T, t+1}^{*}, C_{N, t+1}^{*}\right)}{U_{C_{T}}\left(C_{T, t+1}^{*}, C_{N, t+1}^{*}\right)} \frac{P_{T, t+1}^{*}}{P_{N, t+1}^{*}} .
\end{aligned}
$$

The results of Proposition A.1 and Corollary A.1 apply to this model. 


\section{Are Gold and Dollar global currencies?}

One may wonder whether the emphasis on cryptocurrencies as emerging global currencies is misplaced. Is gold not already a globally acceptable means of payment? Isn't the Dollar already a global currency? The purpose of this section is to shed some light on these questions, complementing the literature discussion in subsection 1.1. We investigate them more deeply in the companion paper Benigno et al. (2022).

Gold First, consider the case of gold. Nowadays, it is hard or even impossible to make payments directly with gold: it is rare to find a shop which would accept it as a means of payment. The reasons can be verification issues (measurement of purity), the risk of fraud, the lack of normalization (size of a gold bar), or the inconvenience due to its weight. Moreover, gold offers benefits beyond those of a fiat currency: gold can be turned into jewelry or used for a variety of medical or industrial purposes. In addition, random findings of gold act as exogenous shocks to the gold supply and thus its price. This may also impede the gold's store of value functionality (see the abandonment of the Gold Standard). In sum, gold is rarely used as a medium of exchange, which is the focus and the basis for our analysis. For that reason, gold does not constitute a global currency, as analyzed in this paper.

Dollarization Next, consider the Dollar. Indeed, international invoicing is often done in terms of Dollar, see Gopinath et al. (2020), and the Dollar serves as a vehicle currency, see e.g. Rey (2001). These papers, however, emphasize the "unit of account" function of money. "Dollarization" often means only the invoicing in terms of Dollar, thus concerning the numeraire function of money, and not its usage as a medium of exchange. However, in some countries often plagued by high inflation rates, physical Dollars are regularly used as a means of payment. As such, this type of Dollarization implies substitution mechanisms with a local currency similar to those emphasized in this work. Though, there are some caveats to consider. Dollarization is an asymmetric phenomenum for which Dollar circulates together with a local currency. On 
the opposite, the local currency does not circulate in U.S. Our analysis on restraining monetary policy also applies to this context. For the local currency to circulate with the Dollar, its interest rate should be capped by the Dollar interest rate. Monetary policy in the dollarized economy then becomes constrained, but not the U.S. monetary policy. Similarly, the literature on Dollarization has found that the return on the two currencies competing in a local market should be the same, e.g. Giovannini and Turtelboom (1992), restating, therefore, Kareken and Wallace (1981) result. Uribe (1997), instead, provides a model in which the decision to adopt Dollars depends on the degree of dollarization. In this way, multiple equilibria arise and the value of the inflation rate can discriminate the prevailing equilibrium, full dollarization or absence of dollarization. In any case, our analysis differs from this literature since it considers competition coming from a global currency, which does not necessarily belong to any jurisdiction, in markets in which local sovereign currencies are circulating. In this context, we derive implications for the local currencies' monetary policies and exchange rates by looking at their relationship from an international perspective rather than just focusing on the national dimension. Indeed, we derive restrictions on cross-country interest rates and exchange rates - something that has not been the focus of the literature on dollarization. Whereas Dollars or another sovereign currency could as well represent the global currency of our model, a worldwide adoption of sovereign currencies in its paper form has not been seen so far. By contrast, a cryptocurrency, unlinked at birth from any sovereign entity, may dramatically alter the financial landscape, once it becomes widely adopted as a medium of exchange in advanced countries through the World-Wide-Web. Similarly, central bank digital currencies may become global means of payments, depending on the particular arrangements chosen by the issuing central bank ${ }^{12}$

\footnotetext{
${ }^{12}$ For two recent examples, note that the "sand dollar" CBDC issued by Bahamas is only available to its residents so far. Likewise, China has declared that it does not wish for its emerging e-yuan to circulate internationally. Whether e.g. the e-yuan will remain a strictly national currency remains to be seen, of course.
} 


\section{Conclusion}

Starting from a general framework, we analyze a two-country economy featuring a home, a foreign and a global (crypto)currency. For the benchmark case that markets are complete, that the global currency is used in both countries and that currency liquidity services are immediate, we show that nominal interest rates must be equal and that the exchange rate between the home and the foreign currency is a risk-adjusted martingale. We call this phenomenon Crypto-Enforced Monetary Policy Synchronization (CEMPS). It adds a further restriction to the classic Impossible Trinity. We discuss the dangers for monetary policies that seek to circumvent this restriction. We characterize the implications for the exchange rate dynamics and the pricing dynamics of the global currency. If the global currency is backed by interest-bearing assets, additional and tight restrictions on monetary policy arise. We demonstrate that our general framework encompasses a number of classic monetary models, such as the Lagos-Wright model, models featuring money-in-the-utility function, and cash-in-advance models. In the appendix, we extend our results to the case of delayed liquidity services. There, we also discuss the general case

where currencies are not perfect substitutes, providing robustness of our global currency deterrence result. We conclude that the introduction of a globally used currency may substantially change the landscape of international monetary policy.

\section{References}

Alberto Alesina and Robert J. Barro. Dollarization. American Economic Review, AEA Papers \& Proceedings, 91(2):381-385, May 2001.

Mary Amiti, Oleg Itskhoki, and Jozef Konings. Dominant currencies how firms choose currency invoicing and why it matters. Working Paper Research 353, National Bank of Belgium, 2018. 
Saleem Bahaj and Ricardo Reis. Jumpstarting an international currency. Technical Report 874, Bank of England, Staff Working Paper, 2020.

Pierpaolo Benigno. Monetary policy in a world of cryptocurrencies. CEPR Discussion Paper No. DP13517, 2019.

Pierpaolo Benigno, Linda Schilling, and Harald Uhlig. Competing means of payments: Bitcoin, credit cards and gold. draft, University of Bern, 2022.

Aleksander Berentsen. Monetary implications of digital money. Kyklos, 51: 89-117, 1998.

Bruno Biais, Christophe Bisiere, Matthieu Bouvard, and Catherine Casamatta. The blockchain folk theorem. The Review of Financial Studies, 32(5):1662-1715, 2019a.

Bruno Biais, Christophe Bisière, Matthieu Bouvard, and Catherine Casamatta. Blockchains, coordination, and forks. In AEA Papers and Proceedings, volume 109, pages 88-92, 2019b.

Luigi Bocola and Guido Lorenzoni. Financial crises, dollarization, and the lending of last resort in open economies. American Economic Review, 110 (8):2524-2557, August 2020.

James M. Boughton. On the origins of the fleming-mundell modell. Technical Report 1, IMF Staff Papers, 2003.

Markus K Brunnermeier and Dirk Niepelt. On the equivalence of private and public money. Journal of Monetary Economics, 106:27-41, 2019.

Ryan Chahrour and Rosen Valchev. The international medium of exchange. draft, Boston College, July 2019.

Jonathan Chiu and Thorsten V. Koeppl. The economics of cryptocurrencies-bitcoin and beyond. Staff Working Paper, Document de travail du personnel 2019-40, Bank of Canada, Banque Du Canada, 2019. 
Lawrence Christiano, H'usn'u Dalgic, and Armen Nurbekyan. Financial dollarization in emerging markets: Efficient risk sharing or prescription for disaster? NBER Working Papers 29034, National Bureau of Economic Research, July 2021.

John H Cochrane. Asset pricing: Revised edition. Princeton University Press, 2009.

Lin William Cong and Zhiguo He. Blockchain disruption and smart contracts. The Review of Financial Studies, 32(5):1754-1797, 2019.

Zahra Ebrahimi, Bryan Routledge, and Ariel Zetlin-Jones. Getting blockchain incentives right. Technical report, Carnegie Mellon University Working Paper, 2019.

Sebastian Edwards and I. Igal Magendzo. Dollarization and economic performanc: what do we really know? International Journal of Finance and Economics, 8:351-363, 2003.

Barry Eichengreen, Arnaud Mehl, and Livia Chitu. How Global Currencies Work: Past, Present, and Future. Princeton University Press, Princeton, NJ, 2017.

Charles Engel. Exchange rates, interest rates, and the risk premium. American Economic Review, 106(2):436-474, 2016.

Jesús Fernández-Villaverde and Daniel Sanches. Can currency competition work? Journal of Monetary Economics, 106:1-15, 2019.

J Marcus Fleming. Domestic financial policies under fixed and under floating exchange rates. Staff Papers, 9(3):369-380, 1962.

Rodney Garratt and Maarten RC van Oordt. Why fixed costs matter for proof-of-work based cryptocurrencies. Available at SSRN, 2019.

Rodney Garratt and Neil Wallace. Bitcoin 1, bitcoin 2,...: An experiment in privately issued outside monies. Economic Inquiry, 56(3):1887-1897, 2018. 
Alberto Giovannini and Bart Turtelboom. Currency substitution. NBER Working Papers 4232, National Bureau of Economic Research, December 1992.

Lance Girton and Don Roper. Theory and implications of currency substitution. Journal of Money, Credit and Banking, 13(1):12-30, 1981.

Linda S Goldberg and Cédric Tille. Vehicle currency use in international trade. Journal of international Economics, 76(2):177-192, 2008.

Gita Gopinath and Jeremy C. Stein. Banking, trade and the making of a dominant currency. NBER Working Papers 24485, National Bureau of Economic Research, April 2018.

Gita Gopinath, Emine Box, Camila Casas, Frederico J. Díez, Pierre-Olivier Gourinchas, and Mikkel Plagborg-Møller. Dominant currency paradigm. American Economic Review, 110(3):677-719, 2020.

Pierre-Olivier Gourinchas, Hélène Rey, and Maxime Sauzet. The international monetary and financial system. NBER Working Papers 25782, National Bureau of Economic Research, April 2019.

Friedrich Hayek. Denationalising money: the argument refined, 1978.

Gur Huberman, Jacob Leshno, and Ciamac C Moallemi. Monopoly without a monopolist: An economic analysis of the bitcoin payment system. Bank of Finland Research Discussion Paper 27, Bank of Finland, 2017.

Ethan Ilzetzki, Carmen M. Reinhart, and Kenneth S. Rogoff. Why is the euro punching below its weight? NBER Working Papers 26760, National Bureau of Economic Research, February 2020.

Jewon Ju. The relationship between currency substitution and exchange rate volatility. thesis, University of California, Berkeley, 2020.

John Kareken and Neil Wallace. On the indeterminacy of equilibrium exchange rates. The Quarterly Journal of Economics, 96(2):207-222, 1981. 
Paul R Krugman. Vehicle currencies and the structure of international exchange, 1979.

Ricardo Lagos and Randall Wright. A unified framework for monetary theory and policy analysis. Journal of Political Economy, 113:463-484, June 2005.

Ricardo Lagos, Guillaume Rocheteau, and Randall Wright. Liquidity: A new monetarist perspective. Journal of Economic Literature, 55(2):371440, 2017.

Jacob D Leshno and Philipp Strack. Bitcoin: An axiomatic approach and an impossibility theorem. American Economic Review: Insights, 2(3):269-286, September 2020.

Robert E. Lucas and Nancy L. Stokey. Money and interest in a cash-in-advance economy. Econometrica, 55(3):491-513, 1987.

Matteo Maggiori, Brent Neiman, and Jesse Schreger. The rise of the dollar and fall of the euro as international currencies. AEA Papers and Proceedings, 109:521-26, May 2019.

Rodolfo E Manuelli and James Peck. Exchange rate volatility in an equilibrium asset pricing model. International Economic Review, pages 559-574, 1990.

Ramon Marimon, Juan Pablo Nicolini, and Pedro Teles. Inside-outside money competition. Journal of Monetary Economics, 50(8):1701-1718, 2003.

Kiminori Matsuyama, Nobuhiro Kiyotaki, and Akihiko Matsui. Toward a theory of international currency. The Review of Economic Studies, 60(2): 283-307, 1993.

Robert A. Mundell. The monetary dynamics of international adjustment under fixed and flexible exchange rates. Quarterly Journal of Economics, 74:227257, May 1960. 
Robert A Mundell. Capital mobility and stabilization policy under fixed and flexible exchange rates. Canadian Journal of Economics and Political Science/Revue canadienne de economiques et science politique, 29(4):475-485, 1963.

Maurice Obstfeld. International risk sharing and the costs of trade. Ohlin Lectures, Stockholm School of Economics, 2007.

Maurice Obstfeld and Kenneth Rogoff. Global implications of self-oriented national monetary rules. The Quarterly Journal of Economics, 117(2):503$535,2002$.

Maurice Obstfeld and Kenneth S. Rogoff. Foundations of International Macroeconomics. MIT Press, Cambridge, MA, 1996.

Maurice Obstfeld, Jay C. Shambaugh, and Alan M. Taylor. The trilemma in history: Tradeoffs among exchange rates, monetary policies, and capital mobility. Technical Report 94, DNB Staff Reports, 2003.

Julien Prat and Benjamin Walter. An equilibrium model of the market for bitcoin mining. Journal of Political Economy, 129(8), 2021.

Hélène Rey. International trade and currency exchange. The Review of Economic Studies, 68(2):443-464, 2001.

Hélène Rey. Dilemma not trilemma: the global financial cycle and monetary policy independence. Technical report, National Bureau of Economic Research, 2015.

David Romer. Comment on" globalization and monetary control". In International Dimensions of Monetary Policy, pages 77-87. University of Chicago Press, 2007.

Linda Schilling and Harald Uhlig. Some simple bitcoin economics. Journal of Monetary Economics, 106:16-26, 2019a. 
Linda Schilling and Harald Uhlig. Currency substitution under transaction costs. Available at SSRN 3314249, 2019b.

Stephanie Schmitt-Grohé and Martín Uribe. Stabilization policy and the costs of dollarization. draft, Columbia University, 2000.

Michael Sockin and Wei Xiong. A model of cryptocurrencies. NBER Working Papers 26816, National Bureau of Economic Research, March 2020.

Harald Uhlig and Taojun Xie. Parallel digital currencies and sticky prices. draft, University of Chicago, May 2021.

Martín Uribe. A simple model of currency substitution. Journal of Monetary Economics, 40(1):185-202, 1997.

Neven T. Valev. The hysteresis of currency substitution: currency risk vs. network externalities. Journal of International Money and Finance, 29: 224-235, 2010.

Carl E. Walsh. Monetary Theory and Policy, 2nd edition. MIT Press, Cambridge, MA, 3rd edition, 2010.

Michael Woodford. The optimum quantity of money. Handbook of monetary economics, 2:1067-1152, 1990.

\section{Appendix}

\section{A Proofs}

\section{A.1 Proof of Proposition 4.2}

Proof. [Proposition 4.2] We have

$$
\begin{aligned}
E_{t}\left[\mathcal{M}_{t+1} \frac{Q_{t+1}}{Q_{t}}\right] & =E_{t}\left[\mathcal{M}_{t+1}^{*} \frac{Q_{t+1}^{*}}{Q_{t}^{*}}\right] \leq 1-L_{t}^{*}=E_{t}\left[\mathcal{M}_{t+1}^{*}\right] \\
& =\frac{1}{1+i_{t}^{*}}<\frac{1}{1+i_{t}}=E_{t}\left[\mathcal{M}_{t+1}\right]=1-L_{t}
\end{aligned}
$$


The first step follows by market completeness. The second and third step follow from equality in (12) and inequality in (13): since the global currency may or may not be in use in country $f$, it yields a weakly lower risk-adjusted return than currency $f$ in country $f$. The fourth step uses equation (8). The fifth step, the inequality sign, is implied by the assumption $i_{t}<i_{t}^{*}$. The sixth step uses equation (7) and the final step follows from the assumption that currency $h$ is used in country $h$, i.e. (9) holds with equality. Thus, $E_{t}\left[\mathcal{M}_{t+1} \frac{Q_{t+1}}{Q_{t}}\right]<1-L_{t}$ and the global currency is not used in country $h$. We directly see that $L_{t}<L_{t}^{*}$ from our derivation. By market completeness $E_{t}\left[\mathcal{M}_{t+1} \frac{S_{t+1}}{S_{t}}\right]=E_{t}\left[\mathcal{M}_{t+1}^{*}\right]<E_{t}\left[\mathcal{M}_{t+1}\right]$ where the last step follows from the derivation above. Therefore, $S_{t}$ follows a supermartingale in the country- $h$ risk-adjusted measure. Vice versa, $E_{t}\left[\mathcal{M}_{t+1}^{*}\right]<E_{t}\left[\mathcal{M}_{t+1}\right]=E_{t}\left[\mathcal{M}_{t+1}^{*} \frac{S_{t}}{S_{t+1}}\right]$. Thus, with $S^{*}=1 / S, E_{t}\left[\mathcal{M}_{t+1}^{*}\right]<E_{t}\left[\mathcal{M}_{t+1}^{*} \frac{S_{t+1}^{*}}{S_{t}^{*}}\right]$ and also the exchange rate from the perspective of country $f$ follows a submartingale.

\section{A.2 Proof of Proposition 4.3}

Proof. [Proposition 4.3] We have

$$
\begin{aligned}
E_{t}\left[\mathcal{M}_{t+1}\right] & =\frac{1}{1+i_{t}}<\frac{1}{1+i_{t}^{*}}=E_{t}\left[\mathcal{M}_{t+1}^{*}\right] \\
& \leq 1-L_{t}^{*}=E_{t}\left[\mathcal{M}_{t+1}^{*} \frac{Q_{t+1}^{*}}{Q_{t}^{*}}\right]=E_{t}\left[\mathcal{M}_{t+1} \frac{Q_{t+1}}{Q_{t}}\right] \leq 1-L_{t}
\end{aligned}
$$

Here the first step uses equation (7). The second step uses the policy set in the two countries, $i_{t} \geq i_{t}^{*}$, the third step equation (8). The fourth step and inequality follows because currency $f$ may or may not be used in country $f$. The fifth step uses that the global currency is used in country $f$. The sixth step uses completeness of markets and the last step uses that the global currency may or may not be adopted in country $h$. Altogether, $E_{t}\left[\mathcal{M}_{t+1}\right]<1-L_{t}$ for $i>i^{*}$. Alternatively, $E_{t}\left[\mathcal{M}_{t+1}^{*}\right]<1-L_{t}^{*}$, if currency $f$ is not used in country $f$, and thus $E_{t}\left[\mathcal{M}_{t+1}\right]<1-L_{t}$ for $i_{t}=i_{t}^{*}$. 


\section{A.3 Proof of Proposition 5.1}

Proof. [Proposition 5.1] (i) Assume $\phi_{t}<i_{t}$. Then $1-L_{t} \geq E_{t}\left[\mathcal{M}_{t+1} \frac{Q_{t+1}}{Q_{t}}\right]=$ $\left(1+i_{t}-\phi_{t}\right) E_{t}\left[\mathcal{M}_{t+1}\right]>E_{t}\left[\mathcal{M}_{t+1}\right]$. The first inequality holds by (10), the second step holds by (21), the third step follows from $i_{t}>\phi_{t}$. Since $1-L_{t}>E_{t}\left[\mathcal{M}_{t+1}\right]$, local currency $h$ is not used. Given the assumption that at least one currency is used in country $h,(10)$ has to hold with equality, $1-L_{t}=\left(1+i_{t}-\phi_{t}\right) E_{t}\left[\mathcal{M}_{t+1}\right]$, and the global currency is used in $h$. By no arbitrage, a comparison between the return on the global currency and the bond through (7) yields $\frac{1-L_{t}}{1+i_{t}-\phi_{t}}=$ $\frac{1}{1+i_{t}}$ and thus $L_{t}=\frac{\phi_{t}}{1+i_{t}}$.

(ii) Assume $\phi_{t}=i_{t}$, then $1-L_{t} \geq E_{t}\left[\mathcal{M}_{t+1} \frac{Q_{t+1}}{Q_{t}}\right]=\left(1+i_{t}-\phi_{t}\right) E_{t}\left[\mathcal{M}_{t+1}\right]=$ $E_{t}\left[\mathcal{M}_{t+1}\right]$ and since at least one currency has to be in use, we have $1-L_{t}=$ $E_{t}\left[\mathcal{M}_{t+1} \frac{Q_{t+1}}{Q_{t}}\right]=E_{t}\left[\mathcal{M}_{t+1}\right]$, implying that both currencies are used.

(iii) Assume $\phi_{t}>i_{t}$, then $1-L_{t} \geq E_{t}\left[\mathcal{M}_{t+1}\right]>\left(1+i_{t}-\phi_{t}\right) E_{t}\left[\mathcal{M}_{t+1}\right]=$ $E_{t}\left[\mathcal{M}_{t+1} \frac{Q_{t+1}}{Q_{t}}\right]$. Thus, the global currency is not used. But since one currency has to be used, it has to be currency $h, 1-L_{t}=E_{t}\left[\mathcal{M}_{t+1}\right]$.

\section{A.4 Proof of Proposition 6.1}

Proof. [Proposition 6.1] Equation (30) and its foreign-country counterpart together with the complete markets assumption deliver

$$
L_{t} a_{2, t}=1-E_{t}\left[\mathcal{M}_{t+1} \frac{Q_{t+1}}{Q_{t}}\right]=1-E_{t}\left[\mathcal{M}_{t+1}^{*} \frac{Q_{t+1}^{*}}{Q_{t}^{*}}\right]=L_{t}^{*} a_{2, t}^{*}
$$

and thus the second claim. Use (29) as well as $1-E_{t}\left[\mathcal{M}_{t+1}\right]=i_{t} /\left(1+i_{t}\right)$ together with its foreign-country counterparts to see that

$$
\frac{i_{t}}{1+i_{t}} \frac{a_{2, t}}{a_{1, t}}=L_{t} a_{2, t}=L_{t}^{*} a_{2, t}^{*}=\frac{i_{t}^{*}}{1+i_{t}^{*}} \frac{a_{2, t}^{*}}{a_{1, t}^{*}}
$$

and thus (34). 


\section{A.5 Proof of Lemma 6.1}

Proof. [Lemma 6.1 ] Concavity and constant returns to scale imply ${ }^{13}$ that

$$
a_{1}(\bar{m}, 0) \leq a_{1}(m, g) \leq a_{1}(0, \bar{g}) \quad \text { and } \quad a_{2}(0, \bar{g}) \leq a_{2}(m, g) \leq a_{2}(\bar{m}, 0)
$$

for all $0 \leq m \leq \bar{m}$ and $0 \leq g \leq \bar{g}$. This implies (36).

\section{A.6 Proof of Proposition 6.2}

Proof. [Proposition 6.2] Equations (31) and (32) holding with equality imply

$$
1=\frac{i_{t}^{*}}{1+i_{t}^{*}} \frac{a_{2, t}^{*}}{a_{1, t}^{*}}+E_{t}\left[\mathcal{M}_{t+1}^{*} \frac{Q_{t+1}^{*}}{Q_{t}^{*}}\right]
$$

where we have used $E_{t}\left[\mathcal{M}_{t+1}^{*}\right]=1 /\left(1+i_{t}^{*}\right)$. The inequality (39) implies

$$
\begin{aligned}
1-E_{t}\left[\mathcal{M}_{t+1}\right] & =\frac{i_{t}}{1+i_{t}}>\frac{i_{t}^{*}}{1+i_{t}^{*}} \frac{a_{2, t}^{*}}{a_{1, t}^{*}} \frac{a_{1}\left(0, g_{t}\right)}{a_{2}\left(0, g_{t}\right)}=\left(1-E_{t}\left[\mathcal{M}_{t+1}^{*} \frac{Q_{t+1}^{*}}{Q_{t}^{*}}\right]\right) \frac{a_{1}\left(0, g_{t}\right)}{a_{2}\left(0, g_{t}\right)} \\
& =\left(1-E_{t}\left[\mathcal{M}_{t+1} \frac{Q_{t+1}}{Q_{t}}\right]\right) \frac{a_{1}\left(0, g_{t}\right)}{a_{2}\left(0, g_{t}\right)} \geq L_{t} a_{2, t} \frac{a_{1}\left(0, g_{t}\right)}{a_{2}\left(0, g_{t}\right)} \geq L_{t} a_{1, t}
\end{aligned}
$$

where we have used the complete-market assumption in the first equality on the second line and where we have used ${ }^{14} a_{2, t}=a_{2}\left(m_{t}, g_{t}\right) \geq a_{2}\left(0, g_{t}\right)$ as well as $a_{1}\left(0, g_{t}\right) \geq a_{1}\left(m_{t}, g_{t}\right)=a_{1, t}$. Thus, the home currency is not used.

\section{A.7 Proof of Corollary 6.2}

Proof. [Corollary 6.2] This is a straightforward generalization of (34). The proof there applies verbatim here, when $a_{1, t}^{*}$ and $a_{2, t}^{*}$ denote the partial derivatives $a_{1}^{*}\left(m_{t}^{*}, g_{t}^{*}\right)$ and $a_{2}^{*}\left(m_{t}^{*}, g_{t}^{*}\right)$ of $a^{*}$ rather than $a$ with respect to the first respectively second argument and evaluated at $m_{t}^{*}$ and $g_{t}^{*}$.

\footnotetext{
${ }^{13}$ For example, note that $a_{1}(m, g)=a_{1}((\bar{g} / g) m,(\bar{g} / g) g) \leq a_{1}(0, \bar{g})$.

${ }^{14}$ It stands to reason that $m_{t}=0$, but we would have to prove that this is so, if we were to use that. Instead, note e.g. that $a(m, g)=\phi(m / g) g$ for some concave function $\phi$. Calculate $a_{12}(m, g)=-\phi^{\prime \prime}(m / g) m / g^{2} \geq 0$.
} 


\section{A.8 Proof of Proposition 6.3}

Proof. [Proposition 6.3] Consider first equation (10) and write it as

$$
\begin{aligned}
1 & =L_{t}+E_{t}\left[\frac{Q_{t+1}}{Q_{t}} \mathcal{M}_{t+1}\right] \\
& =L_{t}+\frac{1}{1+i_{t}} E_{t}\left[\frac{Q_{t+1}}{Q_{t}}\right]+\operatorname{cov}_{t}\left(\frac{Q_{t+1}}{Q_{t}}, \mathcal{M}_{t+1}\right) .
\end{aligned}
$$

in which, in the second line, we have used covariance properties and Assumption 6.1. As well, we can write (13) as

$$
1=L_{t}^{*}+E_{t}\left[\frac{Q_{t+1}}{Q_{t}} \frac{S_{t}}{S_{t+1}} \mathcal{M}_{t+1}^{*}\right],
$$

having used $Q_{t}=S_{t} Q_{t}^{*}$. We can manipulate the above equation, using again covariance properties and Assumption 6.1 to get

$$
\begin{aligned}
1 & =L_{t}^{*}+E_{t}\left[\frac{Q_{t+1}}{Q_{t}}\right] E_{t}\left[\mathcal{M}_{t+1}^{*} \frac{S_{t}}{S_{t+1}}\right]+\operatorname{cov}_{t}\left(\frac{Q_{t+1}}{Q_{t}}, \mathcal{M}_{t+1}^{*} \frac{S_{t}}{S_{t+1}}\right) \\
& =L_{t}^{*}+\frac{1}{1+i_{t}} E_{t}\left[\frac{Q_{t+1}}{Q_{t}}\right]+\operatorname{cov}_{t}\left(\frac{Q_{t+1}}{Q_{t}}, \mathcal{M}_{t+1}^{*} \frac{S_{t}}{S_{t+1}}\right) .
\end{aligned}
$$

Combining (84) and (85), we obtain

$$
L_{t}=L_{t}^{*}+\operatorname{cov}_{t}\left(\frac{Q_{t+1}}{Q_{t}}, \mathcal{M}_{t+1}^{*} \frac{S_{t}}{S_{t+1}}-\mathcal{M}_{t+1}\right) .
$$

Using (9) and (12), we obtain equation (48). 


\section{FOR ONLINE PUBLICATION APPENDIX}

\section{A Robustness analysis}

In this section, we present several robustness analysis of our main results. First, we investigate the case in which liquidity services are delayed by one period with respect to when money is held in the agents' portfolio. Second, we sketch out the implications of imperfect substitutability between currencies. Finally, we provide a detailed model involving credit cards.

\section{A.1 Delayed liquidity services}

An important assumption of our framework is liquidity immediacy, i.e. that the liquidity services provided by a currency occur at the same date $t$ that money is added to the agent's portfolio. However, some models, such as the third example in Section 7, postulate instead that liquidity premia are to be received a period after portfolio choices are made, i.e. with delay in $t+1$ :

Assumption A.1 (Liquidity delay). The purchase of the global currency and currency $h$ in country $h$ at $t$ yields delayed liquidity premia $L_{t+1}$ receivable in $t+1$. Analogously, the time $t$ purchase of global currency and currency $f$ in country $f$ at $t$ yields delayed liquidity premia $L_{t+1}^{*}$ receivable in $t+1$.

In this case, equations (9), (10) and (11) need to be replaced with

$$
\begin{aligned}
1 & \geq E_{t}\left[\mathcal{M}_{t+1}\left(1+L_{t+1}\right)\right] \\
Q_{t} & \geq E_{t}\left[\mathcal{M}_{t+1}\left(1+L_{t+1}\right) Q_{t+1}\right] \\
\frac{i_{t}}{1+i_{t}} & \geq E_{t}\left[\mathcal{M}_{t+1} L_{t+1}\right]
\end{aligned}
$$

The liquidity premia are appropriately discounted by the stochastic discount factor. Since we focus on equilibria in which all currencies are used, we set (A.1), (A.2), (A.3) with an equality sign. 
In country $f$, one must likewise replace (12), (13) and (14) with

$$
\begin{aligned}
1 & \geq E_{t}\left[\mathcal{M}_{t+1}^{*}\left(1+L_{t+1}^{*}\right)\right] \\
Q_{t}^{*} & \geq E_{t}\left[\mathcal{M}_{t+1}^{*}\left(1+L_{t+1}^{*}\right) Q_{t+1}^{*}\right] \\
\frac{i_{t}^{*}}{1+i_{t}^{*}} & \geq E_{t}\left[\mathcal{M}_{t+1}^{*} L_{t+1}^{*}\right] .
\end{aligned}
$$

Again, in what follows, we will assume that the above equations hold with an equality sign. Define the conditional covariance under the home country risk-adjusted measure as

$$
\widetilde{\operatorname{cov}}_{t}(X, Y) \equiv \widetilde{E}_{t}[X Y]-\widetilde{E}_{t}[X] \tilde{E}_{t}[Y]
$$

For a random variable $X$, define the risk-adjusted expectation in country $f$ as the equivalent to $\tilde{E}_{t}[\cdot]$ via

$$
\tilde{E}_{t}^{*}[X] \equiv \frac{E_{t}\left[\mathcal{M}_{t+1}^{*} X\right]}{E_{t}\left[\mathcal{M}_{t+1}^{*}\right]}
$$

Let

$$
\Delta_{t} \equiv i_{t}-i_{t}^{*}
$$

be the differences between the nominal interest rates. Maintaining all other assumptions, we next turn to deriving implications for the exchange rate. The next results apply independently of whether liquidity premia are delayed, and they need as input solely the interest rate differential, like in (A.11).

Proposition A.1 (Delayed Liquidity Services and Exchange Rates)

In a stochastic economy, assuming liquidity delay, complete markets, and all currencies being used: the expected liquidity services differences and exchange rates then satisfy

$$
\Delta_{t}=\tilde{E}_{t}\left[L_{t+1}\right]-\tilde{E}_{t}^{*}\left[L_{t+1}^{*}\right]
$$

and

$$
\frac{\tilde{E}_{t}\left[S_{t+1}\right]}{S_{t}}=1+\frac{\Delta_{t}}{1+i_{t}^{*}}
$$


This corollary is a strict consequence of the given interest differential: the presence of the global currency is not necessary to establish these consequences. Note how the results here are adjusted relative to the expressions in our benchmark result. The (expected) liquidity services now differ by the interest rate differential. If the rate is zero, as in the main result, so is the (expected) liquidity service difference. The exchange rate is no longer a risk-adjusted martingale: instead, there is an adjustment term that depends on the interest rate differential. If that interest rate differential is zero, as in the main result, we are back to the risk-adjusted martingale.

Proof. [ Proposition A.1] Note that (A.1) and (A.3) can be written as

$$
i_{t}=\tilde{E}_{t}\left[L_{t+1}\right]
$$

Likewise, (A.4) and (A.6) can be written as

$$
i_{t}^{*}=\tilde{E}_{t}^{*}\left[L_{t+1}^{*}\right]
$$

The combination yields (A.9). Finally, consider the uncovered-interest-parity relationship (18) to obtain (A.10).

Corollary A.1 (Stochastic Economy under Delayed Liquidity Premia)

In a stochastic economy, assuming liquidity delay, complete markets, and all currencies being used, the nominal interest rate differential satisfies

$$
i_{t}^{*}-i_{t}=\frac{\widetilde{\operatorname{cov}}_{t}\left(L_{t+1}-L_{t+1}^{*}, Q_{t+1}\right)}{\tilde{E}_{t}\left[Q_{t+1}\right]}+\frac{\widetilde{\operatorname{cov}}_{t}\left(L_{t+1}^{*}, S_{t+1}\right)}{\tilde{E}_{t}\left[S_{t+1}\right]}
$$

Note that the benchmark result of interest rate equality in case of liquidity immediacy is a direct consequence of (A.11), since the conditional covariance terms must be zero, if $L_{t+1}$ and $L_{t+1}^{*}$ are known in $t$. In the general case, nonzero covariance terms arise and equation (A.11) informs us, in which direction one needs to adjust the interest differential.

Proof. [ Corollary A.1.] Since all currencies are used, (A.3) and (A.6) hold with equality. With (7) and (8), rewrite (A.3) and (A.6) using the risk-adjusted 
measures as

$$
i_{t}=\tilde{E}_{t}\left[L_{t+1}\right]
$$

and

$$
i_{t}^{*}=\tilde{E}_{t}^{*}\left[L_{t+1}\right]=\frac{\tilde{E}_{t}\left[L_{t+1}^{*} S_{t+1}\right]}{\tilde{E}_{t}\left[S_{t+1}\right]}
$$

where in the latter we have also used the assumption of complete markets. Combining the two equations above, we can write the interest-rate differential as

$$
i_{t}^{*}-i_{t}=\tilde{E}_{t}\left[L_{t+1}^{*}\right]-\tilde{E}_{t}\left[L_{t+1}\right]+\frac{\widetilde{\operatorname{cov}_{t}}\left(L_{t+1}^{*}, S_{t+1}\right)}{\tilde{E}_{t}\left[S_{t+1}\right]},
$$

Note that this equation holds, regardless of whether there is a global currency or not. The presence of the global currency, however, delivers a restriction on the difference between the expected liquidity services. Use (A.5) together with the assumption of complete markets and the equivalence $Q_{t}=S_{t} Q_{t}^{*}$ to obtain

$$
Q_{t}=E_{t}\left[\mathcal{M}_{t+1}\left(1+L_{t+1}^{*}\right) Q_{t+1}\right]
$$

This can be written under the risk-adjusted measure as

$$
\left(1+i_{t}\right) Q_{t}=\tilde{E}_{t}\left[\left(1+L_{t+1}^{*}\right) Q_{t+1}\right]
$$

Writing (A.2) using the risk-adjusted measure

$$
\left(1+i_{t}\right) Q_{t}=\tilde{E}_{t}\left[\left(1+L_{t+1}\right) Q_{t+1}\right]
$$

and compare it with the equation above to obtain that

$$
0=\tilde{E}_{t}\left[\left(L_{t+1}^{*}-L_{t+1}\right) Q_{t+1}\right]
$$

and thus

$$
\tilde{E}_{t}\left[L_{t+1}^{*}\right]-\tilde{E}_{t}\left[L_{t+1}\right]=\frac{\widetilde{\operatorname{cov}_{t}}\left(L_{t+1}-L_{t+1}^{*}, Q_{t+1}\right)}{\tilde{E}_{t}\left[Q_{t+1}\right]},
$$

Plugging (A.19) into (A.14) delivers (A.11). 
Note that equation (A.19) determines the expected difference in the liquidity premia, by which we can retrieve the result of the benchmark case of equal liquidity premia when $L_{t+1}$ and $L_{t+1}^{*}$ are known at time t.

\section{B Imperfect Substitutability of currencies: Lin- ear Scaling}

In this section, we model the imperfect substitutabiliy of currencies per assuming that the liquidity services provided by the global currency are a linear multiple of the liquidity services provided by official domestic currency. In order to frame this approach and and as a general starting point, suppose that liquidity services, $L_{t}^{G}$ and $L_{t}^{G \text {,* }}$ are paid on global currency at home respectively abroad. Let $L_{t}^{H}$ and $L_{t}^{F}$ the liquidity services on home and foreign currency. By imperfect substitutability, we can generically have $L_{t}^{H} \neq L_{T}^{G}$ and $L_{t}^{F} \neq L_{t}^{G, *}$. The pricing equations at home become

$$
\begin{aligned}
& 1 \geq L_{t}^{H}+E_{t}\left[\mathcal{M}_{t+1}\right] \\
& 1 \geq L_{t}^{G}+E_{t}\left[\mathcal{M}_{t+1} \frac{Q_{t+1}}{Q_{t}}\right]
\end{aligned}
$$

with equality when the according currency is used. At foreign, we have

$$
\begin{aligned}
& 1 \geq L_{t}^{F}+E_{t}\left[\mathcal{M}_{t+1}^{*}\right] \\
& 1 \geq L_{t}^{G, *}+E_{t}\left[\mathcal{M}_{t+1}^{*} \frac{Q_{t+1}^{*}}{Q_{t}^{*}}\right] .
\end{aligned}
$$

again with equality if the currencies are used. We maintain the assumption that in each country at least one currency is used and we focus on the case where the global currency is held in at least one country, i.e. where the global 
currency has value. We retain the bond pricing equations

$$
\begin{aligned}
& E_{t}\left[\mathcal{M}_{t+1}\right]=\frac{1}{1+i_{t}} \\
& E_{t}\left[\mathcal{M}_{t+1}^{*}\right]=\frac{1}{1+i_{t}^{*}}
\end{aligned}
$$

Lemma B.1. Without loss of generality, assume the global currency is used abroad. Then $L_{t}^{G} \leq L_{t}^{G, *}$, and it holds $L_{t}^{G}=L_{t}^{G, *}$ if and only if the global currency is used in both countries.

Lemma B.1. Without loss of generality, assume the global currency is used abroad. Then $1=L_{t}^{G, *}+E_{t}\left[\mathcal{M}_{t+1}^{*} \frac{Q_{t+1}^{*}}{Q_{t}^{*}}\right]=L_{t}^{G, *}+E_{t}\left[\mathcal{M}_{t+1} \frac{Q_{t+1}}{Q_{t}}\right] \leq 1-L_{t}^{G}+L_{t}^{G, *}$, where the second step uses that the global currency is traded arbitrage-free in international capital markets. If the global currency is not traded at home,

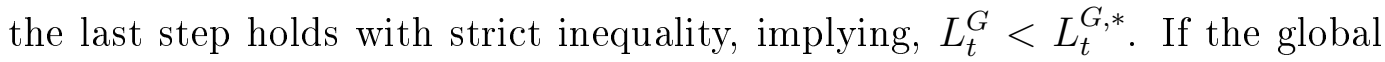
currency is traded at home, the last step holds with equality, implying $L_{t}^{G}=$ $L_{t}^{G, *}$. Vice versa, $L_{t}^{G}=L_{t}^{G, *}$ requires the global currency to be traded at home.

Proposition B.1 (Imperfect Substitutability)

Assume $L_{t}^{H}=\xi L_{t}^{G}$ and $L_{t}^{F}=\xi^{*} L_{t}^{G, *}$ where $\xi, \xi^{*}>0$. Assume that the home currency is used at home and that the foreign currency is or is not used at the foreign country. Assume the global currency is used at the foreign country. Consider $\left(i^{*}, \xi, \xi^{*}\right)$ with $i_{t}^{*}>0$.

a) If $\xi<\xi^{*}$ or $\xi>\xi^{*}$ and $i_{t}^{*} \in\left(0, \frac{1}{\frac{\xi}{\xi^{*}}-1}\right)$ then the global currency is not adopted at home if the home central bank sets $i_{t}>0$ which satisfies

$$
i_{t}<\frac{1}{\frac{\xi^{*}}{\xi}\left(1+\frac{1}{i_{t}^{*}}\right)-1}
$$

b) If $\xi>\xi^{*}$ and $i_{t}^{*} \in\left(\frac{1}{\frac{\xi}{\xi^{*}}-1}, \infty\right)$ then for every $i_{t}>0$, the global currency is not adopted at home.

c) If $\xi=\xi^{*}$, then the global currency is not adopted at home if the home central bank sets $i_{t}<i_{t}^{*}$. 
Proof. Assume, the global currency is used at the foreign country. The previous Lemma B.1 jointly with the bond pricing equations yield that the global currency is not used at home if

$$
\begin{aligned}
0<L_{t}^{G, *}-L_{t}^{G} & =\frac{1}{\xi^{*}} L_{t}^{F}-\frac{1}{\xi} L_{t}^{H} \\
& \leq \frac{1}{\xi^{*}}\left(1-\frac{1}{1+i_{t}^{*}}\right)-\frac{1}{\xi}\left(1-\frac{1}{1+i_{t}}\right) \\
& =\frac{1}{\xi^{*}}\left(\frac{1}{1+1 / i_{t}^{*}}\right)-\frac{1}{\xi}\left(\frac{1}{1+1 / i_{t}}\right)
\end{aligned}
$$

which is equivalent to requiring

$$
1 / i_{t}>\frac{\xi^{*}}{\xi}\left(1+1 / i_{t}^{*}\right)-1
$$

Case 1: Assume $\xi<\xi^{*}$. Then for all $i_{t}^{*}>0$ : $\frac{1}{i_{t}^{*}}>0>\frac{\xi}{\xi^{*}}-1$ and thus $\frac{\xi^{*}}{\xi}\left(1+\frac{1}{i_{t}^{*}}\right)-1>0$. Thus, the right hand side of (B.30) is strictly positive and the inequality (B.30) can only hold for $i_{t}$ satisfying (B.26). In that case, the global currency is not adopted at home.

Case 2: Assume $\xi>\xi^{*}$.

Case 2a: Assume in addition $i_{t}^{*} \in\left(0, \frac{1}{\frac{\xi}{\xi^{*}}-1}\right)$. Then, again, the right hand side of (B.30) is strictly positive and the inequality (B.30) can only hold for $i_{t}$ satisfying (B.26). In that case, the global currency is not adopted at home.

Case 2b: Assume $\xi>\xi^{*}$ and $i_{t}^{*} \in\left(\frac{1}{\frac{\xi}{\xi^{*}}-1}, \infty\right)$. Then, the right hand side of (B.30) is negative. Therefore, every $i_{t}>0$, satisfies B.30. Thus, for every $i>0$ the global currency is not adopted at home.

Case 3: For $\xi=\xi^{*}$, then inequality (B.30) simplifies to

$$
1 / i_{t}>1 / i_{t}^{*}
$$

So that the global currency is not adopted at home for every $i_{t}<i_{t}^{*}$. 